\title{
Improvement of the Computing-Related Procurement Process at a Government Research Facility
}

\author{
C. Gittins
}

April 3, 2000 


\section{DISCLAIMER}

This document was prepared as an account of work sponsored by an agency of the United States Government. Neither the United States Government nor the University of California nor any of their employees, makes any warranty, express or implied, or assumes any legal liability or responsibility for the accuracy, completeness, or usefulness of any information, apparatus, product, or process disclosed, or represents that its use would not infringe privately owned rights. Reference herein to any specific commercial product, process, or service by trade name, trademark, manufacturer, or otherwise, does not necessarily constitute or imply its endorsement, recommendation, or favoring by the United States Government or the University of California. The views and opinions of authors expressed herein do not necessarily state or reflect those of the United States Government or the University of California, and shall not be used for advertising or product endorsement purposes.

Work performed under the auspices of the U. S. Department of Energy by the University of California Lawrence Livermore National Laboratory under Contract W-7405-Eng-48.

This report has been reproduced directly from the best available copy.

Available to DOE and DOE contractors from the

Office of Scientific and Technical Information

P.O. Box 62, Oak Ridge, TN 37831

Prices available from (423) 576-8401

http://apollo.osti.gov/bridge/

Available to the public from the National Technical Information Service

U.S. Department of Commerce 5285 Port Royal Rd., Springfield, VA 22161 http://www.ntis.gov/

OR

Lawrence Livermore National Laboratory Technical Information Department's Digital Library http://www.llnl.gov/tid/Library.html 


\section{Improvement of the Computing-Related Procurement Process at a Government Research Facility}

A project report presented to Saint Mary's College

In partial fulfillment of the requirements for the degree of

Bachelor of Arts in Management

By

\section{Candace Gittins}

MSN15

April 3, 2000 



\section{Table of Contents}

\section{Page}

$1.0 \quad$ Executive summary......................................... 1

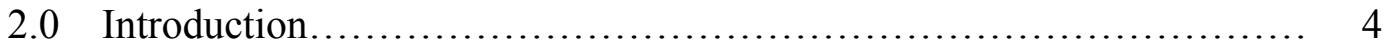

2.1 Organizational background............................... 4

2.2 Nature of problem..................................... 4

2.3 Changes impacting the problem........................... 6

2.4 Overview of Literature Review.............................. 8

3.0 Historical analysis: chronological detail, problems, and resolutions...... 10

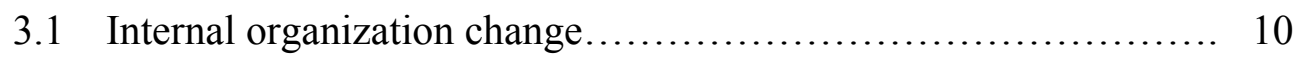

3.1.1 Assessment...................................... 10

3.1.2 Reorganization..................................... 15

3.1.3 CRC Online...................................... 19

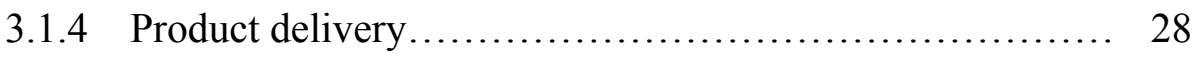

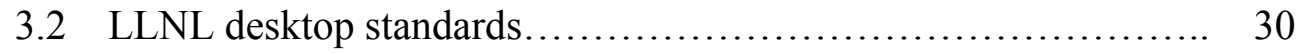

3.2.1 Hardware/software standards and savings.............. 30

3.2.2 Hardware maintenance agreements................... 36

3.2.3 Legato enterprise agreement....................... 44

3.2.4 Oracle enterprise agreement....................... 47

3.3 Computer Acquisition Specialist program................... 50

4.0 Historical analysis: evaluation results.......................... 62

4.1 Restatement of purpose and objectives...................... 62

4.2 Evaluation of project objectives........................... 62

4.2.1 Objective One................................... 62

4.2 .2 Objective Two..................................... 62

4.2.3 Objective Three.................................... 68

4.3 Evaluation of project budget.............................. 70 
4.4 Evaluation results..................................... 71

5.0 Conclusions and recommendations................................ 77

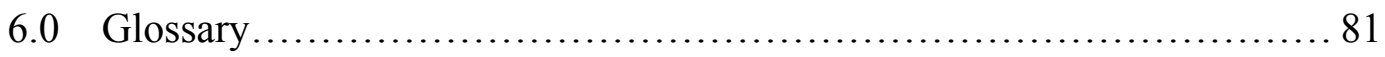

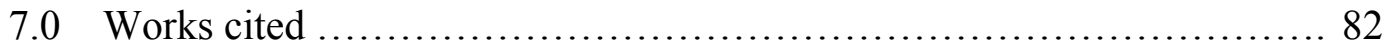

8.0 Appendices.............................................. 83

Appendix A, Project Proposal

Appendix B, Project Plan

Appendix C, Literature Review

Appendix D, Assessments

Appendix E, CRC Customer Service Surveys

Appendix F, Help Desk Call Tracking Statistics

Appendix G, CRC Online Pages

Appendix H, CRC Online Articles

Appendix I, LLNL Software Standards

Appendix J, PC and Mac Desktop Configurations

Appendix K, Statement of Services/Price List and Equipment Schedule

Appendix L, ISM Enrollment Letter

Appendix M, Compaq (Digital) Maintenance Agreement

Appendix N, Grumman Systems Support

Appendix O, Legato Enterprise License for LLNL

Appendix P, Oracle Network License

Appendix Q, Computer Acquisition Specialist

9.0 Oral Presentation.................................................. 84 


\subsection{Executive Summary}

In May 1995, a center for providing computing-related products and services to employees of a Government research laboratory was formed. The center would become an onsite store for the procurement of computers, workstations, peripherals, printers, software and other computing-related commodities. Through services subcontracts, volume purchase agreements, and site licenses, the center would also provide institutional computing-related products and services.

Self-supporting and available to serve a laboratory-wide customer base of approximately 8,000 employees, the center's operating budget is totally recovered through a fee-for-service tax applied to each customer order. The center's staff is comprised of five commodity buyers and three contract administrators, one receiving and warehouse person, one database developer, one buyer assigned to a matrix position, and one manager.

Even though the center serves a lab-wide customer base, it is not a sole source facility. In fact, it has approximately four hundred competitors in the form of buyers, called technical release representatives working in various departments throughout the laboratory. The center faces criticism for its value-added fee-for-service, and is constantly threatened by various political factions with closure.

Historically, each department of the Government research laboratory has acted independently. With the introduction of the personal computer into this cultural environment, each group did what it had done before. That is, each procured different computer platforms and employed different networking tools and capabilities. Each organization hired is own support personnel to handle its own installed base. There was 
no thought or planning given to a computing infrastructure. There were no standards, no centralization, and no common ground. The result was redundancy of effort and waste. This lack of computing infrastructure put the Laboratory at a disadvantage. An area of concern then was how to leverage the functionality and services of the computer center to better serve the overall computing-related needs of the institution.

The purpose of the management project has two parts: To support and streamline the computing-related procurement function at the institution, and to lower the total cost of desktop computing through standardization, site licensing, volume-purchasing, and selected outsourcing of services. The project will improve customer service and implement value-added services and products at the computer center. Improving center operations and implementing new center services will give laboratory personnel more reason to have contact with the facility.

The project will also provide value to the institution through streamlining the computing-related procurement process, thereby saving institutional dollars. This will be accomplished by lowering total cost of ownership through site licensing and procuring software, hardware, and other computing-related services based on volume discount.

Specific and measurable project objectives were to increase the customer base of the center by 10 percent, improve customer service ratings by 25 percent, and streamline computing-related procurement practices within the distributed organizations by $15-20$ percent in fiscal year 1999 and 35 percent in fiscal year 2000.

Achieving the project objectives required a reassessment of and changes to the internal operations of the computer center. It also required implementation and marketing of new services, and promotion of a computer acquisition specialist program to 
organizations throughout the laboratory. Research provided guidance for improving customer service, marketing, and implementing the change process.

The project manager views the project as a partial success. Objective one was realized as the CRC customer base increased 9.6 percent during the period March 1999 through February 2000, while the number of systems enrolled under its various service agreements increased by 39 percent. Objective two was partially realized when a comparison between the first and second CRC customer surveys revealed an overall 13.4 percent increase in an excellent rating.

Objective three, to streamline computer-related procurement practices within $15-20$ percent of the distributed organizations in fiscal year 1999 and 35 percent in fiscal year 2000, has not been realized. Two organizations have chosen to use the CRC facility as their primary source for computing-related products and services. Even though these decisions resulted in a 17 percent increase in procurement practice in fiscal year 1999, there were no organizations willing to adopt the computer acquisition specialist program. It is anticipated that there will be three directorates ready to implement the program by fiscal year 2001 . 


\subsection{Introduction}

\subsection{Organizational background}

This world-class research facility has been in existence since 1945, and is best known for its contributions to nuclear science. The facility is operated by the University of California under the auspices of the US Department of Energy. Historically, the facility has been organized by disciplines, with funding received from a wide variety of disparate sources. Under this scenario, each organization, rather loosely defined by scientific discipline, has developed its own management structure and acts autonomously from other organizations. In the late 1980's this distributed management structure and work environment began to feel the effects of the introduction of the desktop, personal computer.

\subsection{Nature of problem}

In the beginning, the personal computer was a complement to the distributed environment giving programs greater flexibility and even more autonomy than before. However, the infrastructure required to support this kind of computing environment became very difficult to manage. Under the distributed model, each organization was making its own information technology decisions and building its own information technology infrastructure. These uncoordinated decisions and practices lead to a mixture of mismatched equipment, systems, networks, and services, resulting in redundancy and waste. Management of this computing environment became a technical and logistical nightmare.

In 1995, the LLNL Director formed an information task force for the purpose of reviewing internal practices, procedures and policies with an eye toward eliminating 
redundancy and waste. After a lengthy review, this Cost Cutting Initiative identified making improvements in the Laboratory's information technology activities a top priority. Approximately one year later the laboratory director selected a Chief Information Officer and within another year, the Chief Information Officer established the Systems and Network Department (SND).

The SND was chartered with responsibility to streamline desktop computing support functions, eliminate redundancy and waste, and lower information technology costs. In order to accomplish its mission, the SND needed to create an organizational structure that would pull together multiple organizations, disciplines, and people into a functional whole. The resulting SND organization has two main components: the Computer Support Units, where groups of technical staff are housed with and provide support to the various laboratory departments, and Central Operations. Each Computer Support Unit is "built around groups of customers" (Bateman \& Snell, 1996, p. 252) in a geographical area where computer support personnel provide networking, software, hardware, and consulting services to computer users. "The primary advantage of [this approach] to departmentalization is the ability to focus on customer needs and provide faster, better service. But again, duplication of activities across many customer groups and geographic areas is expensive" (p. 252). To help mitigate this problem, each Computer Support Unit manager, or Client Liaison, reports to a central manager located in the department office. Central Operations performs complementary functions to the computer support units and the laboratory as a whole. Central Operations is comprised of three parts, the Help Desk, the SouRCe (System Administrator Resource Center), and the Computing Resource Center. Each component performs a specific function from 
handling laboratory-wide computer support inquiries (Help Desk), to providing imaging, programming and integration services (SouRCe), and the procurement of computingrelated products and services (Computing Resource Center). Central Operations could be defined as a form of "product departmentalization" (Bateman \& Snell, 1996, p. 250), with each unit offering a specific type of service or product.

The management project resides in the SND Computing Resource Center (CRC). The CRC was established in May 1995, for the purpose of providing computing-related products and services to employees of the research facility. Already in existence at the time the SND was formed, the CRC became part of the newly formed organization. Today, the center continues as a self-supporting unit funded through a fee-for-service assessed to each customer order.

The CRC is in a unique position to help the SND meet part of its mission to streamline and standardize information technology. Implementation of the management project has helped provide focus and guidance for this effort: To support and streamline the computing-related procurement function at the laboratory, and to lower the total cost of desktop computing through standardization, site licensing, volume-purchasing, and selected outsourcing of services.

\subsection{Changes impacting the problem}

In order to meet these objectives the project has several components. Each of these will be discussed in greater detail in the following pages. However, it must be noted that at nearly every turn, the project manager met various distractions and impediments that worked to alter or delay the outcome of the original goal. For example, in the spring of 1999, the LLNL was suddenly impacted by reviews of its internal safety and security- 
related policies and practices. The oversight was dramatic and sudden, causing the facility to shutdown for two separate one-week periods for the purpose of re-training all employees in these areas. The greatest impact of this oversight was on computer security and consequently the SND was sent into a tailspin of activity directed toward finding and eliminating computer security-related problems.

Unfortunately, the pressure of this activity meant that all other projects were set aside until the SND professionals and management could get to them. It is also anticipated that this nearly frenetic activity will continue into the future. As a consequence, portions of the management project were put on hold until those who were part of the process could be available for meetings and discussions. At the same time, site licensing and volume procurements of security-related products moved quickly forward. Another impact of the crisis was recognition by executive management of the need for standardization as a necessary component to resolving the information technology dilemma.

Another factor leading to a detour in direction for the management project was dramatic and unexpected cutbacks in funding for the research facility. The CRC felt the impact of the cutbacks as a loss of business revenue, leading to an unexpected need to change its internal structure. The decreased funding also made it difficult, if not impossible, to make a case for the recruitment of personnel to become computer acquisition specialists assigned to work with computer support personnel within each directorate and department.

These organizational changes have lead to a delay in the project goal of moving the decentralized computing-related procurement function into one that is centrally 
dispatched from the $\mathrm{CRC}$ into the various programs. Additional resistance to this idea has not come because the departments and directorates do not agree with the value of the idea. Instead, the greatest resistance has come because its adoption will require a need to change the structure of the procurement process within each organization. Again, a distributed rather than consolidated cultural view became the key deterrent to the computer acquisition specialist portion of the project. The project manager will review the outcome of each of these efforts in greater detail in the following pages.

\subsection{Overview of Literature Review}

Three areas of the literature review provided a basis and guide for the project. Of primary importance were writings on customer service, electronic commerce, and implementing organizational change. One component of the management project is to increase the customer base of the CRC. Gathering information about the facility's current and potential customers through a variety of methods was an important step in this process.

The customer information gathering process was handled in a variety of ways: person-to-person, customer surveys, and focus groups. One of the best sources for getting information about customers is from internal-to-the-organization staff. "Anyone who has contact with customers - sales, telemarketing, public relations, accounting, and the service group — picks up bits and pieces of information" (Halbrooks, 1996, p. 192). The CRC customer survey, Help Desk database, and contract focus groups have all contributed to the overall improvement of CRC customer service. 
In the area of electronic commerce, Customers.com contained a wealth of information on designing a successful electronic business. The author's five-step strategy for success was used in the development of CRC Online. These steps follow:

6.0 "Make it easy for customers to do business with you

7.0 Focus on the end customer for your products and services

8.0 Redesign your customer-facing business processes from the end customer's point of view

9.0 Wire your company for profit by designing a comprehensive, evolving electronic business architecture

10.0 Foster customer loyalty" (Seybold, 1998, p. 60).

Internal CRC processes were assessed and reorganized. Effectively managing this change was an integral part of the management project. The research advocated open and honest communication as important tools in helping people gain a feeling of personal control over the transition process. Authors Arun Maira and Peter Scott-Morgan provide a guide for creating a continually changing organization. The following four principles were of particular interest:

- Managing for strategic flexibility

- Managing for change-readiness

- Managing for organization involvement

- Managing for learning acceleration

The premise is that changed processes might deliver results, but processes do not learn. Instead, "people learn and people cause processes to improve and perform" (Maira \& Scott-Morgan, 1997, p. 2). 


\subsection{Historical analysis: chronological detail, problems and resolutions}

\subsection{Internal organization change}

\subsubsection{Assessment}

In April 1999, the project manager began a reassessment of the internal organization of the CRC. This reassessment was prompted by four primary factors: 1) A changing business model, 2) Conflicts among staff members 3) Increasing operational costs, and 4) Feedback from a February 1999 customer service survey.

Due to the nature of its business, the CRC must continually reevaluate and revise its operating procedures and processes in order to meet the needs of its customers. In concert with this continuous improvement process, during the spring of 1999, new service activities were added to the group that challenged its operating budget and stretched its work capacity. It was evident to the project manager that in order for the CRC to manage these changes while maintaining current staffing levels and fee-for-service rates, changes to its internal operations would have to be made. As a by-product of the process, it was hoped that the changes would result in greater efficiency and improved customer service.

The CRC is located in a large warehouse-like facility where its Technical Release Representative (TRR) buying staff are situated on an open floor, with high industrial ceilings. Noise, heating and cooling, and high maintenance costs are ongoing areas of concern. Before the group was reorganized, the TRRs worked in two-person teams. Each team handled a combination of commodity-related procurements and subcontract administration services. The two individuals were seated in close proximity to each other in a U-shaped configuration, created by utilizing modular furniture and room dividers. The staff came to refer to these work areas as pods and to each other as pod-partners. In 
addition to the four two-person teams, the CRC employed three parts room persons who handled the customer service counter, receiving and property, customer service phone line, and electronic mail orders. These functions were rotated monthly with each employee moving from one functional area to another. At this time, the $\mathrm{CRC}$ also employed a full-time system administrator-stock analyst.

In March 1999, the SND began disbanding a computer repair services team known as Computer \& Network Support. When the group disbanded, its departure had a tangible impact on the CRC and its business. The first impact was seen in the loss of in-house computer repair services for both CRC customers and staff. The second was the need to take on responsibility for vendor repair services; a function previously performed by the Computer \& Network Support team. The vendor repair activity involves coordinating computing-related repair services of LLNL equipment to outside computer repair service companies. Vendor repair represents a 50-75 percent time work effort. The CRC took over responsibility for the service without increasing its staff, operating budget, or feefor-service rate. The project manager assigned the part-time work activity to a CRC buyer.

In April 1999, the CRC received another assignment. This work involved two functions: acting as a liaison for outside service and commodity providers and acting as a member of the Desktop Advisory Group (DAG). The DAG activity involved participation in the LLNL desktop standardization process, with the establishment of site licenses and volume procurements being a key part of that process. The vendor liaison effort also involved interaction with a wide variety of vendors, suppliers, and agencies seeking access to the LLNL. Additional work effort involved coordinating various 
Laboratory-wide seminars, presentations, or vendor events. The vendor liaison work came to the $\mathrm{CRC}$ without funding. The work had previously received institutional funding, but these funds were to be used in another area. As a result, a CRC buyer and the project manager absorbed the vendor liaison work effort.

Partly as a result of the increased workload came feelings of frustration particularly among the staff members being asked to take on additional responsibilities. Another problem causing internal strife was the separation between buyers and parts room personnel. The parts room staff seemed to feel devalued in comparison to the TRR staff and they disliked the rotation schedule. These frustrations were manifested in a lack of communication, arguing and bickering. The work atmosphere was so charged that it began to affect all aspects of the business, particularly customer service. It was clear to the project manager that the situation had to change for many reasons, not the least of which was the fact that a "Dissatisfied or fearful employee can seldom be expected to provide quality service that leads to customer satisfaction" (Chakrapani, 1998, p. 220).

Another issue affecting morale was the lack of consistency between job function and formal job classification, with the most important overriding issue being the attainment of full-time equivalent status. The project manager had been working to resolve these issues, but the process was long and slow and fraught with alternating periods of hope and disappointment. All CRC employees had originally been hired as contract laborers to the LLNL, each at different time periods, under different classifications, with different salaries, from different job shops. An alignment of the job assignments and salaries, together with obtaining FTE status for each employee was a primary objective of the project manager. 
The first step was getting all employees to a classification that provided a more equitable salary distribution. Since it was not possible to move all the employees to FTE status at the same time, the project manager revised the contract labor job descriptions to more clearly reflect the work being performed. This resulted in a reclassification that meant for the majority a move from one labor shop to another, and a significant salary increase. These actions were taken on behalf of CRC personnel prior to the group becoming part of the SND.

At the time of reevaluating the CRC internal organization in April 1999, the project manager met with SND senior management to request approval to hire all CRC employees to full-time equivalent status while also moving them to a more appropriate job classification. The project manager received approval and began to prepare the appropriate reclassification and posting paperwork.

The project manager met with the Human Resources Recruitment and Employment team on April 23, 1999. The team reviewed the proposal, but had issues about moving the employees from administrative to technical positions, and also with a transition from unlimited to limited time status. The project manager went back to rewrite the proposal adding more substantive justification to address both issues.

On May 17, 1999, the project manager reconvened with the human resources team to review the rewritten justification. After a rather extensive question and answer period, the project manager received approval to reclassify all CRC personnel and more importantly to post and fill all the positions at full-time equivalent status.

On May 31, 1999, the job posting appeared in the LLNL Employment Bulletin. The posting ran for the customary two-week period, following which the project manager 
reviewed applications and interviewed qualified candidates. On June 23, 1999, the project manager met with SND management to determine salary levels for the new LLNL CRC employees. On July 7, 1999, the hiring packages were completed and sent forward for department, directorate, and director approvals. On August 15, 1999, CRC employees were contacted and job offers extended.

Another part of the reorganization assessment process was consideration of results from the first CRC customer service survey sent out on February 5, 1999. The survey was delivered by electronic mail to over 1200 customers. The electronic message contained a link to the CRC web page where the customer could respond to the survey and submit his or her response by pointing and clicking with the computer mouse in the appropriate boxes (see Appendix E, CRC Customer Service Surveys).

Survey recipients were asked to rate eight different service categories on a quality scale of Excellent, Fair, or Poor. The survey contained a comments section for customers to add other remarks. The eight service areas were Order convenience, Product knowledge, Timely product receipt, Responsiveness, Problem resolution, Price, Billing accuracy, and Stock availability. Of the over three hundred responses received, the one overwhelming criticism of the survey was "The quality scale is rather limiting. There are levels of quality that fit in between the three provided that might have been beneficial—and more accurate." Soon after receiving these comments, two additional categories were added to the survey: Satisfactory and Unsatisfactory.

Other more significant ratings and remarks lead to a need for improvement in several areas. These areas for improvement were more timely product receipt, better pricing, and increased stock availability. Customers also requested door-to-door delivery 
and order status updates, and the ability to order product online. Areas receiving excellent ratings and remarks included ordering convenience, responsiveness to the customer's needs, and billing accuracy.

Each of the problem areas were identified as focal points for change and three of these, timely product receipt, better pricing, and increased stock would be addressed as part of the internal reorganization process. The order status problem was more easily remedied through the use of an automatic electronic mail message generated through the CRC database. The auto messages notified customers of the date when orders were placed by the buyer, when orders were delayed and the reason for the delay, and when orders were received and ready for pickup. These electronic mail notifications have worked well, preventing CRC customer frustration and saving TRR buyers a lot of avoidable customer complaints.

\subsubsection{Reorganization}

At the beginning of April 1999, the project manager began a series of one-on-one meetings with each CRC staff member. The purpose of these meetings was to elicit an open exchange about career objectives, training needs, and preferences for commodity buying or contract administration work. Armed with information learned at these meetings, the project manager then met with the full staff. During the next several full staff meetings, discussion centered on the customer service survey and resultant feedback from customers. The group brainstormed about ways to improve customer service and respond to customer requests for additional services.

The project manager took all the resultant data and put together different reorganization scenarios. One of these was the development of three teams each team 
with specific day-to-day responsibility together with backup responsibility to another team. For example, Team A would be responsible for ordering all commodities, while Team B would be responsible for custom orders and customer consultations, and Team C would handle contract administration. Teams B and C would provide backup for Team A, Team A would provide backup for Team B and the members of Team C would provide backup for each other.

On April 23, 1999, the staff met and approved the three-team concept. Over the next week, two team members worked to put together several new floor layouts that would accommodate the new team configurations. These layouts were presented at the staff meeting on April 30, 1999. One layout was selected as the optimal choice and over the course of the next several workdays, the office floor space was reorganized. The database was also re-scripted to accommodate the new workflow method. Following is a scenario of how each team would function:

Team A would be comprised of two TRR commodity buyers. The buyers would pull need-to-order scripts from the database twice daily. The first script would be pulled between 8-9:00 AM and the second pulled between 3-4:00 PM. From the orders pulled at these times, the buyers would solicit bids from three or four different vendors. Because all customer orders would now appear on these need-to-order scripts the resulting bids to vendors would be so large that the CRC would obtain optimal pricing based on volume. When the number of orders became too great to be handled effectively, Team B would handle the overflow. 
Team $B$ would also be comprised of two TRR commodity buyers. This team would handle the more difficult custom orders and customer consultations. Team B would receive its orders out of the daily scripts being pulled from the database by Team A.

Team $C$ would be comprised of three TRR contract administrators responsible for the administration of volume purchase, support and maintenance subcontracts. One member of Team $\mathrm{C}$ would also assist the project manager with vendor events and site license procurements.

The customer service counter and help desk responsibilities would be divided among all staff members on a rotation basis. One person would handle receiving and property and one person would handle database and web development.

Soon after everyone had adjusted to the reorganization, CRC staff was faced with year-end procurement volume. During the months of August and September, the CRC receives anywhere from one-third to one-half of its total business volume.

It became clear following the fiscal year ended September 30, 1999, that the new CRC team concept was in need of modification. Due in part to the high volume of orders being processed by Team A, there was a lack of follow-through on distressed items, an inability to monitor stock quantities, and keep up with inventory counts. Another less than positive outcome was a loss of product expertise and the ability to provide solutions to customer problems.

On October 13, 1999, the project manager met with all commodity buyers to begin a dialogue about how to fix these problems, while maintaining optimum volume discount pricing. The commodity buyers were anxious to return to a modification of the old model, wherein each buyer was responsible for specific categories of products. This 
model allowed each buyer the opportunity to become a specialist, rather than generalist in the fast-paced computer technology environment. Specialization also allowed the buyers to become more valuable to $\mathrm{CRC}$ customers as they were able to offer expertise in such diverse areas as cabling, networking, memory, and computer configurations.

The commodities group met on October 20,1999, to determine which products each buyer would handle. In addition to buying the product set, the buyer would also be responsible for determining stock and reorder levels, product research, and inventory. The primary difference between this return to buying categories and its previous model was the continued separation between commodity buying and contract administration.

Once the commodity group was situated, the project manager changed the CRC meeting schedule in an effort to more effectively handle problems and issues closely associated with four main work activities: commodity buying, contract administration, customer service help desk (telephone), and customer service counter. Prior to this time CRC staff meetings were held on a weekly basis every Friday morning from 8:00 AM to 9:30 AM. Under the new meeting schedule, the project manager meets with the commodities group every other Tuesday afternoon, with the contracts group every other Thursday afternoon, with the phone group every other Tuesday morning, with the counter group every other Friday, and with all staff on the opposite Friday morning.

A rather amazing thing happened with the very first commodity "subgroup" meeting. The group became suddenly more willing to converse with each other without pointing fingers and placing blame. For the first time in a very long time, the meetings became productive. Real problems were being solved and staff members were actively participating. 
Another significant change implemented during the second reorganization, was the distribution of the counter and help desk functions equally among all staff members. Each staff person was given a choice between four different counter/help desk schedules. The staff cast a private vote for the option of choice and the winning option was adopted. The counter/help desk rotation resulted in several significant benefits for both CRC staff and CRC customers:

- All staff members became personally involved in providing direct customer service

- All staff members became aware of process and database issues preventing optimum performance

- All staff members became more aware of how his or her behavior and/or actions directly impacted both the internal and external CRC customer

A positive outcome of the second reorganization occurred when the Help Desk group worked together with the data base developer to design a call tracking system. This call tracking database has already been useful in targeting and solving customer service issues. Following is an example of the types of calls handled by Help Desk personnel (see Appendix F, Help Desk Call Tracking Statistics).

\subsubsection{CRC Online}

Customers had expressed a desire for electronic access to CRC parts inventory from the earliest days of center's creation. At one point, the CRC did provide password access to its database server for members of the Computer \& Network Support team. As time passed, it became more and more evident that electronic access was not only 
desirable from a customer-service perspective, but also a key to growth for the organization.

As an organization, the CRC needed to decide what kind of electronic access should be implemented. To aid in this decision, CRC staff began to informally solicit interest from customers, technical staff, and internal and external management sources. This was done in an effort to determine how important electronic access was to users and what kind of access would best fill those needs. For example, should the CRC expand its database server access or should it expand its view by implementing an electronic commerce web site.

Armed with feedback from customers, the CRC decided that developing electronic commerce through the LLNL Intranet was the best choice. In January 1999, the $\mathrm{CRC}$ database programmer began web-based training and mentoring from department programmer staff. In the beginning, the development process was slow, moving forward in alternate starts and stops until it became clear that if the $\mathrm{CRC}$ was going to be successful with its online venture, it was necessary to re-examine and streamline its internal business processes. It became imperative that the CRC develop a new perspective by identifying the end customer, then streamlining the interaction from the customer's point of view. Helping customers do their jobs is an important aspect of electronic commerce as it is an integral part of providing excellent customer service. According to author, Patricia B. Seybold (1998), “Time-pressed customers aren't satisfied to know about price and capabilities; they want to know what you have on hand and how soon they can have it" (p. 251). 
Redesigning its business from the customer's point of view was a new challenge, requiring a new perspective and greater teamwork. The process was difficult and caused some resistance, particularly from staff members not certain that the required expenditure of effort was worth achieving the ultimate goal.

In addition to the job assignment changes taking place within the organization, there were also redesign changes to the database, changes to the physical inventory, and changes to database processes all occurring simultaneously. For example, because online customers would now have access to information in the database through a web interface, that information had to be streamlined in order to be useful to the customer.

As part of the development process, the CRC group began looking at other electronic commerce sites to see what ideas could be gleaned from already successful web sites. Some of the specific sites visited and used were outpost.com, macmall.com, pcmall.com amazon.com, barnes\&noble.com and cdnow.com. The CRC database/web developer was instrumental in bringing this kind of information to the attention of staff members for review and comment. The project manager also enlisted help and expertise from other SND groups and got the CRC developer assigned to a recently created SND web team. The web team had been formed for the purpose of developing a web site for the new department and the project manager had been assigned as a member in April 1999. After several meetings with the group, it was evident that the person who needed to be involved was the CRC database/web developer. CRC Online would become an integral part of the SND web site and the SND web team would provide valuable expertise, review, and oversight for the CRC web development. 
Participation in this group by the CRC developer was key to getting the final product online. The developer had been struggling with the programming and interface aspects of the project. This kind of programming effort was new and unexplored territory for her and it was clear the online project needed a higher level of expertise in order to get on track.

The developer had been informally getting assistance from a programmer assigned to the SND Help Desk. In an effort to jumpstart the CRC Online programming effort, the project manager met with the SND Help Desk manager to set up a more formal arrangement to obtain the services of this programmer. It was determined that the programmer would meet with the CRC developer each afternoon from 4:00-6:00 PM until the development process was at a level where the developer could continue on her own. These afternoon sessions began in May and ended in June 1999.

As anticipated this programming effort was key to getting the online project back on track. Another benefit from this association was that both the programmer and developer learned new skills and expertise in web and database development and design. It should be noted that neither employee had any prior experience with developing an electronic commerce site. With the raw interface completed, it became incumbent on the CRC developer along with help from the CRC staff to enhance the basic system that would eventually serve the needs of the LLNL user community.

This process of refining data and content began in late May and continued until the first beta version of what has become CRC Online was released on July 15, 1999. The first beta was released to a limited audience of fifteen CRC customers, eleven SND managers, and eight members of the SND web team. Feedback was cataloged and 
adjustments made to the process. Following are sample beta comments from the first release:

\#1 Please put the CRC fax \# on the home page.

\#2 My cart had items that I didn't order and I got error messages on some things.

\#3 I feel it would be helpful to somehow guide the customer through the site

\#4 I like the look.

\#5 The page is too big for PC browser. Columns don't get wide enough. There's nothing on the front page to tease visitors. No "Records" should be No "Items" found. Can't always get back to shopping cart from every page.

\#6 Also, the HOME button should go directly to the CRC homepage. You shouldn't encourage customers to leave the site.

\#7 It would be great if in your "Detail Record" section; you had a digital picture of the item.

\#8 The site looks great!

\#9 A picture of the item would be a nice enhancement.

\#10 Thanks for a look at your new online ordering system; I've been hoping for a long time that just such a thing might be available!

\#11 I toured around in here and I really like the look and feel of it. Great job!

\#12 I asked for Mac/Hardware/Video card and got two computers listed.

In the meantime, it was clear that the CRC needed to streamline its data entry processes to eliminate redundancy and errors occurring across all of its some ninety-three different databases. This was an enormous undertaking considering the volume of product and customer information involved. With over 15,000 product records to be reviewed, it was clear that in order to get the work completed, the records would have to be broken down and distributed across the CRC organization. The group determined that the best way to handle the breakdown was by product category. For example, software would be one category, while cabling and networking equipment would be another. Each of the buyers would be responsible for reviewing the records most closely associated with his or her buying category. 
In addition, two employees volunteered to work on clearing out and reorganizing the parts room inventory. To help in this effort each buyer inventoried the products within his or her purview and determined the disposition of product on the shelf. There were three categories into which each of the over three thousand products fell: (1) parts to be retired (2) parts to be sold at a discount, and (3) parts to be kept in stock. These recommendations were reviewed with the project manager, who made the final decision on product disposition.

Through the efforts of these individuals the parts room inventory was reduced from $\$ 350 \mathrm{~K}$ to $\$ 180 \mathrm{~K}$. Part locations were also changed to more easily accommodate the receiving and order filling process. Parts room shelves were relabeled and where possible barcodes applied to enhance the inventory and record keeping process. As part of the reorganization process, each buyer became responsible for the inventory of the products to which they were assigned. For example, the employee responsible for procuring software is also responsible for maintaining the accuracy and viability of the inventory stock. This means keeping up with customer buying trends, customer feedback, and product reviews in order to optimize inventory to meet customer demand.

Use of common naming conventions for creating part numbers and descriptions and entering important product information was also required. With multiple people performing data entry, the database often became collection of nonsensical information. It was clear that this problem needed to be resolved before putting that information in view of the customer base. One of the first steps was to determine exactly what information the customer would see displayed when they logged onto and navigated the CRC web site. 
The group decided that as a first step, only stocked parts would be displayed. The rationale behind this decision was that it gave the group a defined group of products that could be more easily controlled than displaying every part ever ordered. Because some part descriptions could be very long and unwieldy for display as well as difficult for customers to decipher, the CRC developer came up with the idea of creating a part name field. The part name field would be limited to twenty characters and would provide a brief description of the product. This field is displayed next to the part number in the CRC Online display (see Appendix G, CRC Online Pages).

Once the naming conventions were agreed upon, each member of the team took responsibility to ensure that the parts under his or her purview were appropriately named and described. For the next several weeks at each weekly staff meeting, one staff member would display and describe the naming conventions for the products for which they were responsible. The staff would offer suggestions and tips for making the descriptions even more concise and decipherable to the user community. While the CRC staff were working on naming conventions and descriptions in the database, the CRC online developer found and inserted graphics for the visual display of various products (see Appendix G).

CRC Online uses a FileMaker database with a Lasso web engine as the interface between the database and the web page. In order to ensure reliability and speed, the CRC needed to procure a server that could handle the volume of transactions and data storage required for its electronic commerce business running. After reviewing several specifications, seeking counsel from CRC and SND staff, the project manager purchased a Dell PowerEdge 4300, dual 450MHz, Pentium III processor, with $512 \mathrm{MB}$ of memory 
and three 18 GB Raid hard drives, running Windows NT 4.0. In combination with its existing Hewlett Packard server, the CRC will be able to handle the anticipated volume of its online order transactions. Funding for this purchase was obtained from the Systems \& Network Department office.

Soon after receiving the server equipment, the second beta release of CRC Online occurred on September 20, 1999, and was distributed to approximately four hundred users. Again, user comments were solicited and enhancements implemented. The final release of CRC Online Version 1.0 to the general LLNL public occurred on January 3, 2000.

The CRC continues to monitor and receive feedback from its CRC Online customers. We do this by providing a feedback form on each web page. We pay attention to what customers tell us, gather all the results, and then use this information to prioritize our web redesign efforts. We have learned that "customers will tell you exactly what they want and need" (Seybold, 1998, p. 143).

In an effort to promote CRC Online, the project manager took advantage of the following promotional opportunities:

Personal selling defined as "a person-to-person dialogue between buyer and seller" (Zikmund \& d'Amico, 1998, p. 352), is a key component of CRC business. Personal dialogue between customers and staff occurs at the CRC customer service counter where customers gather to place and pickup orders, and over the telephone, when customers call to place or obtain information about orders.

CRC Online was promoted through indirect communication in three onsite publications: a biweekly newspaper, an electronic NewsOnline service, and a 
departmental publication, SND Desktop News (see Appendix H, CRC Online Articles). These publications "have the advantage of mass appeal within selected geographical markets, a general respect in the community, and short lead time" (Zikmund \& d'Amico, 1998, p. 388). Since the CRC did not pay for the use of this media, it should be viewed as publicity or public relations, rather than advertising.

As an Intranet service, CRC Online not only provides a way for customers to shop online, but also provides a forum for feedback about products and services being offered. Internal marketing to $\mathrm{CRC}$ employees is another key component of the marketing mix for CRC Online. This is especially important because CRC employees "have contact with ultimate consumers... [as well as] a direct effect on the ultimate consumer's satisfaction with the product" (Zikmund \& d'Amico, 1998, p. 398). CRC employees are aware that the ultimate success of its business and the online service provides them with continued job satisfaction and security.

To date the most important element to CRC promotion has been personal selling. The "two basic characteristics that contribute to the importance of personal selling are its flexibility and its value in building relationships" (Zikmund \& d'Amico, 1998, p. 411). CRC personnel are adept at making sales presentations in specific situations. Each time a customer contacts the facility, they encounter some form of personal selling from staff members. This may take the form of a one-on-one consultation over which personal computer to buy, or help in selecting the right cable or connector. With the advent of CRC Online, personal selling has expanded to include helping customers to logon and navigate the web site. 


\subsubsection{Product delivery}

Results from the CRC customer service survey made it clear that product delivery was an important value-added service. Currently customers are required to visit the CRC facility to pick up orders. Also, with the implementation of CRC Online, product delivery of online orders is even more important. In order to provide a delivery service utilizing in house personnel, the CRC would need to increase staff and obtain specialized equipment. Because there was no budget to hire additional personnel or equipment, the project manager had to look for other options.

The project manager contacted the LLNL Transportation manager to see if they might be able to accommodate CRC customer delivery needs. Transportation was more than willing to pick up product from the CRC building and deliver it to customers across the site, but there would be a sizable fee assessed for this service. Realizing that CRC customers already felt burdened by high prices because of the fee-for-service rate, this did not seem like an attractive solution to the delivery problem.

Hearing from outside sources that the LLNL Shipping \& Receiving department might be looking into a delivery service program, the project manager contacted the Shipping \& Receiving manager in August 1999. The manager learned that the department was looking into utilizing its afternoon shift as a window of time to provide customer delivery service. This was wonderful news and the project manager asked to be placed on the pilot program for the new service.

Several weeks and even months passed without any further word about the program. Even though the project manager continued to ask for updates, she was always 
told that the program was not ready to launch. In November 1999, she was told the department had decided not to implement the delivery program.

Disappointed, the project manager decided to contact the Transportation group again to see if she might be able to negotiate a lower delivery rate. A meeting with the Transportation manager took place on February 18, 2000. At this meeting the project manager proposed a pilot program between the CRC and Transportation, whereby Transportation personnel would pickup product from the CRC two days per week at 1:00 PM and deliver that product to CRC customers until 4:00 PM. For this guaranteed work assignment, Transportation would give the $\mathrm{CRC}$ a discounted delivery rate.

If the delivery rate were reasonable, the $\mathrm{CRC}$ would be able to absorb the costs into its operating budget, thereby implementing another value-added service without increasing its fee-for-service rate. The CRC would be able to absorb this additional cost by not replacing a recently transferred CRC staff member.

In the meantime, the Shipping and Receiving organization contacted the project manager expressing interest in reintroducing a delivery pilot project for the LLNL. The manager met with two representatives from this group on March 1, 2000. A follow-up meeting took place on March 7, 2000 with the division leader of Materiel Distribution and the manager of Shipping and Receiving. At this meeting the logistics of a delivery plan were discussed and the project manager was asked to write a Memorandum of Understanding for signature by department management.

The $\mathrm{CRC}$ will begin a pilot delivery program for its customers in mid-April. Initially, the costs of this service will be absorbed by the CRC operating budget. The Materiel Distribution Department will set up the necessary equipment and train CRC 
personnel. The CRC will procure a $\$ 300.00$ barcode system. For implementation of the pilot, the CRC database developer will reprogram sections of CRC Online to display and accommodate the required delivery data. The pilot program will be completed on June 30,2000 at which time its value will be assessed.

\subsection{LLNL desktop standards}

\subsubsection{Hardware/software standards and savings}

As part of the Director's Cost Cutting Initiative, an Information Architectural (IA) task force was formed for the purpose of establishing Laboratory standards. An integral part of the IA effort is the role played by the Desktop Advisory Group (DAG). The DAG is composed of representatives from each LLNL directorate. The group meets on a monthly basis for the purpose of developing and implementing software and hardware standards at the LLNL. To date, the DAG has focused its attention on software standards, which are reviewed and updated on a semi-annual basis and posted at the IA web site (see Appendix I, LLNL Software Standards).

The project manager's role as a member of the DAG is to bring software product information, including costs and LLNL usage, to the group for review. If the products require further discussion and/or testing, the SND SouRCe performs this service and either recommends inclusion or exclusion from the standards list. Once a product has been approved, the project manager handles the procurement, marketing to the LLNL user population, updating of the standards list, and electronic or media product distribution. The project manager also keeps track of product updates and site license renewals, informing the DAG of renewal dates and costs. The project manager is 
responsible for managing the site license budget and securing funding approvals for additions or changes to this institutional budget.

The process of establishing software standards and site licensing these products for use by the institution is more cost effective than the distributed method whereby each department made its own procurements. During fiscal year 1999, the LLNL saved approximately $\$ 20 \mathrm{M}$ due to the implementation of software standards and subsequent site licensing, enterprise and volume purchase agreements.

LLNL Site Licenses

\begin{tabular}{|c|c|c|c|c|c|c|}
\hline Vendor & Software & $\begin{array}{c}\text { License Max. } \\
\text { Usage }\end{array}$ & $\begin{array}{c}\text { Estimated } \\
\text { Actual Users } \\
\end{array}$ & Total Cost & Retail Price & $\begin{array}{c}\text { LLNL Estimated } \\
\text { Savings } \\
\end{array}$ \\
\hline Apple & Mac OS & 8000 & 6000 & $\$ 64,950$ & $\$ 99 /$ ea & $\$ 529,050$ \\
\hline Apple & Mac $X$ & 1000 & 1000 & $\$ 73,100$ & $\$ 120 /$ ea & $\$ 25,900$ \\
\hline ASD Software & FileGuard & 5000 & 3500 & $\$ 105,500$ & $\$ 249 /$ ea & $\$ 766,000$ \\
\hline Data Fellows* & F Secure & 12000 & 6000 & $\$ 16,995$ & $\$ 5.90 /$ ea & $\$ 18,405$ \\
\hline Data Viz & Conversions Plus & 5000 & 2500 & $\$ 106,196$ & $\$ 99.95 /$ ea & $\$ 143,679$ \\
\hline FileMaker & FileMaker Pro + & 5000 & 5000 & $\$ 172,000$ & $\$ 199.95 /$ ea & $\$ 827,750$ \\
\hline FileMaker & FileMaker Server & unlimited & 1000 & - & $\$ 999.95 /$ ea & $\$ 999,950$ \\
\hline FileMaker & FM HomePage & unlimited & 1000 & - & $\$ 99.95 /$ ea & $\$ 99,950$ \\
\hline FileMaker & FM Developer & unlimited & 500 & - & $\$ 499.95 /$ ea & $\$ 49,975$ \\
\hline General Technology & NAV Solution & 7000 & 6000 & $\$ 35,443$ & $\$ 57 /$ ea & $\$ 306,557$ \\
\hline On Technology & Meeting Maker & 8000 & 6000 & $\$ 86,000$ & $\$ 75 /$ ea & $\$ 364,000$ \\
\hline Shana & Informed Filler & 8000 & 5000 & $\$ 43,000$ & $\$ 195 /$ ea & $\$ 932,000$ \\
\hline Internet Security Systems* & SAFESuite & 8000 & 8000 & $\$ 4,961$ & $\$ .80 /$ ea & $\$ 1,439$ \\
\hline PowerQuest & Drive Image Pro & 8000 & 2500 & $\$ 1,010$ & $\$ 190 /$ ea & $\$ 473,990$ \\
\hline Qualcomm & Eudora Pro & 8000 & 8000 & $\$ 10,750$ & $\$ 49.95 /$ ea & $\$ 388,850$ \\
\hline Star Division & Star Office & 8000 & 2500 & $\$ 1,010$ & 169/ea & $\$ 421,490$ \\
\hline Subtotal cost and savings & & & $\longrightarrow$ & $\$ 720,915$ & & $\$ 6,348,985$ \\
\hline
\end{tabular}


LLNL Enterprise/VPAgreements

\begin{tabular}{|c|c|c|c|c|c|}
\hline Supplier & Product & Cost @ List & LLNL Cost & $\%$ Discount & $\begin{array}{l}\text { LLNL Estimated } \\
\text { Savings }\end{array}$ \\
\hline Compaq (Digital Services) & Hardware maintenance/repair & $2,208,206$ & $\$ 507,887$ & $77 \%$ & $\$ 1,700,318$ \\
\hline Compaq (Digital Services) & Software maintenance/support & $1,001,050$ & $\$ 690,725$ & $31 \%$ & $\$ 310,326$ \\
\hline Grumman & Sun Unix hardware maintenance & $2,345,638$ & $\$ 351,846$ & $85 \%$ & $\$ 1,993,792$ \\
\hline Legato & Networker suite/license/support & $2,065,217$ & $\$ 475,000$ & $77 \%$ & $\$ 1,590,217$ \\
\hline Oracle & Oracle suite/license/support & $15,258,296$ & $\$ 7,781,731$ & $51 \%$ & $\$ 7,476,565$ \\
\hline SGI & Software maintenance/support & 488,856 & $\$ 48,886$ & $90 \%$ & $\$ 439,971$ \\
\hline SGI & Hardware maintenance/repair & 838,322 & $\$ 461,077$ & $45 \%$ & $\$ 377,245$ \\
\hline Sun & Software maintenance/support & 293,027 & $\$ 152,374$ & $48 \%$ & $\$ 140,653$ \\
\hline Subtotal cost and savings & $\longrightarrow$ & $\$ 24,498,613$ & $\$ 10,469,526$ & & $\$ 14,029,087$ \\
\hline
\end{tabular}

To enable the CRC to more efficiently provide duplicated media of site licensed, enterprise, and volume purchased software, the CRC purchased a duplicating system on June 30, 1999. The equipment includes two drives, with transport robotics for 100 disks, a color CD-R printer, Dell Pentium 400Mhz personal computer with a 9 gigabyte hard drive and software suite: Workstation, Winburn, Image Server, Production Server and CD Designer Label editor. The cost of the equipment was $\$ 23,000.00$ and was partially funded out of the CRC operating budget.

Unlike the implementation of institutional software standards, developing hardware standards at the LLNL presented a more difficult problem. The culture of the LLNL encourages creativity and innovation and discourages control, centralization, and standards. Trying to force users to move to a single platform has been and continues to be difficult and even controversial.

Due in large measure to these kinds of concerns, during the period of September 1997 through September 1999, the DAG deferred to hardware configurations published on a quarterly basis by the $\mathrm{CRC}$. The $\mathrm{CRC}$ develops these configurations based on three criteria: high-end, mid-range, and low-end systems, product availability, and LLNL usage 
patterns. In October 1999, the LLNL Administrative Information Services group published minimum hardware configurations on the Information Architecture web site. In January 2000, a new Information Architecture leader was selected from the Administrative Information Services organization. This individual will now direct the Information Architecture task force and dictate the future activity of the DAG.

While the DAG has grappled with the problem of developing hardware standards for a long time, it has not been complacent in this pursuit. Beginning in February 1999, a series of meetings were coordinated by the project manager for the purpose of implementing site wide hardware standards. These meetings took place with the top five personal computer manufacturers, whose machines are used at the LLNL.

On February 11, 1999, the first meeting took place with representatives from IBM Corporation. The format of this and all subsequent meetings was to describe to vendor representatives what the LLNL was trying to accomplish in the standards arena. The idea being that since these standards could not be forced on the LLNL user, they would have to be attractive enough to seduce users to the standard systems. Choice would also be part of the equation, for example there would be low, medium, and high-end computer processing units to choose from. There would also be two laptop configurations. Each system would come with a standard image configuration established by the LLNL. This image would include the operating system and the LLNL standard software.

The vendor representatives were asked about their company's ability to meet the needs of the LLNL, including the establishment of an electronic commerce web site. Other topics of conversation were property tagging and tracking, use of a value-added reseller, and a process for installing and testing of the LLNL image. 
Following the IBM group, similar meetings were conducted with the following manufacturers:

February 17, 1999, Micron Computer

February 18, 1999, Hewlett Packard

March 22, 1999, Compaq Computer

April 1, 1999, Gateway Computer

April 16, 1999, Dell Computer

The DAG hardware standards subgroup reported its findings to the DAG meeting on April 28, 1999. Even though all the companies could provide the LLNL with the basic standards and services, there were three that stood out because it was felt they offered greater value to the institution. The next step was getting the Procurement \& Materiel Department involved in the process. Procurement \& Materiel would be responsible for determining how the procurement process should proceed. A prime consideration for the institution is the impact of single source procurements on meeting Government social and economic goals. It was determined that another round of manufacturer meetings should be scheduled to which Procurement \& Materiel personnel would be invited to participate. The first of these took place on May 5, 1999 with Compaq Computer, followed by meetings on May 5 with Hewlett Packard, May 13, with Gateway, and May 19 with Micron Computer.

At this point, the LLNL was about to undergo national scrutiny of its security policies and practices. In particular this scrutiny involved computer security. The LLNL in general and the SND in particular were significantly impacted. In fact, the SND standards program lead was completely removed from his normal work assignment to 
work on a special committee established for the purpose of responding to government security concerns. During this time, the LLNL standards project was put on hold.

In September 1999, the Administrative Information Services department became more involved in the standards project resulting in a series of meetings to pick up the process from where it had been left off in late spring. The Business Operations department of which Administrative Information Services is a part had a significant stake in the establishment of hardware standards for the LLNL. Responsible for development of software applications for various LLNL business functions, the Administrative Information Services was particularly interested in developing for a standard platform instead of spending considerable time and effort in ensuring that its software applications would operate on a multitude of hardware platforms.

The meetings with Administrative Information Services began on September 1, 1999, and continued at the rate of one meeting per week until September 28, 1999. As a side activity, the DAG put together a subgroup for the purpose of developing standard configurations for the Macintosh platform. The project manager was a member of this committee and participated in the development of both the PC and Mac desktop configurations (see Appendix J).

Due to some internal issues, the project was once again put on hold where it remained until the new Information Architecture leader was appointed after January 1, 2000. Since that appointment, the project manager together with her manager, have met on a weekly basis with Business Operations personnel to move the standards process forward. It has been decided that one personal computer manufacturer will be selected 
and a request for proposal will be written for the purpose of soliciting proposals from value-added resellers.

At the February 14, 2000 meeting, it was determined to also move forward with standard configurations for the Macintosh platform. This work will not be combined with the personal computer solicitation, but will run in tandem with it.

On February 23, 2000, following the DAG meeting, the project manager suggested to her manager that the CRC should move forward with a pilot program for selling high, medium, and low system configurations for the both the Macintosh and personal computer platforms. The institutional image would be installed into each bundled system. The SND manager approved this idea and as soon as the image is ready, the pilot program will move forward. The CRC could begin selling these standard systems through CRC Online in April 2000.

\subsubsection{Hardware maintenance agreements}

Two hardware maintenance, repair services subcontracts were due to expire at the end of September 1999. Due to historical precedence, contract maintenance services for VAX, Alpha, and Unix systems would require competitive solicitation. In an effort to gain approval for a sole source agreement for these services through the original equipment manufacturer, the project manager put together a proposal for management review. Even though the proposal clearly spelled out the benefits to the institution of original equipment manufacturer support, the proposal was turned down and the process for a competitive award began.

On March 30, 1999, the project manager met for four hours with the Procurement \& Materiel contract representative for the purpose of defining the requirements and 
documentation for the competitive solicitation. Following this meeting, the project manager began preparation of the Statement of Services and Proposed Price List and Equipment Schedule to be used as part of the request for proposal package (see Appendix $\mathrm{K})$.

On May 19, 1999, the project manager met with representatives from Compaq (Digital) services to discuss required elements for the statement of work. On June 28, 1999, the project manager met again with the Procurement \& Materiel contract representative to assist in writing the request for proposal documentation. The project manager recruited two key users of the maintenance services to participate on the buying team as evaluators of the solicitation proposals. The remaining members of the buying team were the Procurement \& Materiel contract representative, the Procurement \& Materiel division leader, two CRC contract administrators and the project manager.

Once the buying team was in place and the request for proposal written and approved by Procurement \& Materiel management, the request for proposal was sent to ten qualified candidates on September 10, 1999. Proposals were due to the LLNL Procurement \& Materiel representative by 3:00 PM on October 7, 1999. On September 28,1999 , the buying team convened to review the proposal documentation and receive instructions and guidance on the evaluation process. This four hour training session prepared the team for the review process.

On October 11, 1999, the buying team met to begin the review process for eight proposals received in response to the request for proposal. The buying team met again on the following dates: October 12, 14, 19, 25, and 29; and November 8, 12, and 16, 1999. Each of the sessions was four to six hours in length. 
On November 16, 1999, having selected two candidates from the request for proposal pool, the buying team needed further clarification of the content of each proposal. On December 8, 1999 the buying team met formally with Vendor A representatives to solicit responses to its concerns. On December 10, 1999, a similar meeting was held with representatives from Vendor B.

Armed with this data the Procurement \& Materiel contract representative began compiling the documentation required for review from the Procurement \& Materiel Contract Review Board. An informal Contract Review Board took place on December 1, 1999, at which time the five-member panel concurred with the buying team recommendation to enter into negotiations with the proposed awardees. A schedule of meetings was established with each contract vendor to obtain proposal clarification and to negotiate on outstanding issues.

Three meetings occurred with Vendor A on December 8 and 13, 1999 and January 24, 2000. During these meetings the following issues were evaluated and approved by the Buying Team and the P\&M contract representative:

1. Pricing on New Technology_-Vendor A's initial proposal did not include a discount of pricing methodology for maintenance on "new technology." New technology is defined as equipment that has been released by Vendor A for a period of twelve months or less. As a result of the negotiations, Vendor A agreed to offer LLNL a 15 percent discount for maintenance on new technology. The discount will be applied to the "uplift" price between standard warranty (typically 9 hours/day, 5 days/week, next day response) to a higher level of service, perhaps 9 hours/day, 5 days/week, with a four hour 
response. The 15 percent discount would then be applied to the difference between the two service levels.

2. Warranty Pricing-Vendor A clarified that warranty pricing applies to equipment newly purchased by the LLNL that is covered by the original equipment manufacturer's standard warranty, yet is considered "old technology" (i.e. has been released more than twelve months). If an end-user desired to uplift a piece of equipment under warranty to a higher level of service, Vendor A would calculate the difference between the basic price for maintenance and the price to uplift the machine to a higher level of service. The difference between the two coverage amounts would then be discounted by the applicable discount.

3. Time \& Materials Repair Rates-In its initial proposal, Vendor A offered time and material rates of $\$ 150$ per hour with no specified time minimums and $\$ 150$ for travel. The negotiated time and material pricing has been changed to $\$ 150 /$ hour with a two-hour minimum and no travel charge.

4. Increase in Discount - In its initial proposal, Vendor A offered a discount of 62 percent for machine type $\mathrm{X}$ and 70 percent discount for machine type $\mathrm{Y}$. The negotiated price for this service is now 63 percent for $\mathrm{X}$ machines and 73 percent for Y machines.

Based on the content of these meetings and negotiations with Vendor A, the LLNL will also realize cost-savings by combining its current software maintenance contract with the hardware contract. The combination of these two services into one contract provides the LLNL with a 31 percent versus current 24 percent discount on 
software maintenance. Vendor A offered the additional discount in response to combining hardware and software maintenance into one agreement and extending the term of the combined agreements from three to five years. This negotiation will save the LLNL (based on currently enrolled systems) $\$ 707,520.00$ over the five-year contract term A proposal clarification and negotiation meeting was scheduled with Vendor B on December 10, 1999. The buying team and the P\&M contract representative were able to reach favorable negotiation results on the following issues:

1. Onsite Field Service Engineer-Vendor B will provide a dedicated onsite field service engineer in addition to maintaining an area to house spare parts commonly needed for repairs. Vendor B will establish the onsite FSE within a 90-day time period following contract award. This FSE will be housed with the $\mathrm{CRC}$ and the project manager will provide administrative oversight.

2. Pricing Source-The buying team had previously indicated to Vendor B the importance and necessity of obtaining a copy of the price list from which Vendor B's discounts were derived and where list prices exist. Vendor B adamantly stated that in accordance with its agreement with the original equipment manufacturer they were prohibited from providing this price book. In order for the $\mathrm{CRC}$ contract administrator to verify and audit prices, it is imperative that LLNL have access to Vendor B's pricing source. In an effort to reach accommodation on this issue, the $\mathrm{CRC}$ contract administrator met with a Vendor B representative to compare the original equipment manufacturer's price book with the price list used by Vendor B in response to the proposal. They determined that no discrepancies exist between the two 
pricing sources. It is believed that prior to the August time frame, the original equipment manufacturer provided different pricing sources: One type for resellers and another type for end-users. Because no variation in pricing was recognized between the pricing sources, the pricing source used by the CRC will be the original equipment manufacturer price list

3. Revised Pricing and Discounts - The buying team determined that it would be interested in improvements to some of the performance features offered by Vendor B. Vendor B agreed that these feature improvements were possible but they would require modest pricing adjustments. The revised pricing offered would increase the LLNL monthly cost by $\$ 6,700$. Because the value of these features is less than the proposed cost, the revised pricing still represents a significant saving to the LLNL in relation to the current services provided by Vendor B.

Based on the content of the December 10, 1999 meeting and subsequent telephone negotiations with Vendor B, the LLNL will realize a cost saving of $\$ 8,550$ per month for a higher level of service over the term of the three-year agreement.

On February 18, 2000, the Procurement \& Materiel contract representative presented the results of the request for proposal and evaluation process for review and approval to a nine-member contract review board. The contract review board requested minor changes. These changes were made and the contract was sent to both Vendors A and B on February 22, 2000 for review and signature. The effective date of both agreements was March 1, 2000 
Toward the end of the evaluation process, the project manager received notification from the Procurement \& Materiel department that onsite repair work performed by any outside contractor was prohibited under recently released safety requirements. The LLNL had implemented a new Department of Energy-mandated safety program called Integrated Safety Management (ISM).

The ISM guidelines required that each individual user (the person requesting service) complete the required ISM documentation prior to any work activity being performed. Meeting this guideline would be impossible under the current terms and conditions of the hardware services contract. Initially, it appeared that the only way to meet the ISM guideline was to cancel the new service subcontracts. This would result in each group or department setting up its own contract (a distributed approach) rather than taking advantage of the volume purchase achieved by combining all systems under one agreement.

The project manager was asked to find a way to meet the ISM guidelines while making it possible for the site-wide agreement to be implemented for the LLNL user community. The project manager first informed her management of the situation, but received little support for finding an equitable solution. She next met with representatives from the Environmental Safety \& Health Department to determine what documentation would be acceptable under ISM requirements. The ISM documentation required a definition of and number designation for the work activity. This work activity level is determined by defining the hazards associated with each aspect of the work to be performed. For example, a work activity level one is defined as an activity that can be performed without specialized training. Any work activity level designation greater than 
one requires additional safety documentation. The project manager was able to get written approval from the Environmental Safety \& Health Division Leader on November 24, 1999 for the repair work to be designated as a work activity level one. Unfortunately three weeks before the new contracts were to be implemented, the Procurement \& Materiel safety officer was successful in having the Environmental Safety \& Health ruling overturned, meaning that the contract was once again in jeopardy.

On January 27, 2000, the project manager met with her Environmental Safety \& Health team to determine an approach that would enable the services contract to be approved and the maintenance work to continue. Following a determination of approach, the project manager called a meeting of all interested parties: Procurement \& Materiel representatives, user representatives, Environmental Safety \& Health representatives, and SND management. At this meeting, she outlined the approach worked out with Environmental Safety \& Health and received approval to move forward.

The next step was to identify any hazards associated with the computer repair work. The project manager met with service engineers from both Vendor A and Vendor B, together with LLNL technical staff to obtain this information. She then prepared the Hazards List, had it approved by Environmental Safety \& Health, and forwarded it to the Procurement \& Materiel contract representative for inclusion in the contract agreement.

The next step was to prepare an enrollment letter for current and potential users of the service (see Appendix L, ISM Enrollment Letter). This letter describes the program and the user's responsibility to (1) ensure that work performed meets the definition of a facility activity level one, or (2) take the necessary steps to obtain approval for and complete the appropriate documentation for a facility activity level greater than one. 
The hardware services subcontracts were awarded to Compaq Computer and Grumman Service corporations effective March 1, 2000. On March 23, the first rollout meeting was held with users and potential users of the Compaq services agreement. The project manager presented the contents of the subcontract to the LLNL user community (see Appendix M, Compaq (Digital) Maintenance Agreement). On April 6, the second rollout meeting will be held with current and potential Grumman users (see Appendix N, Grumman System Support).

Following the rollout meetings and enrollment period, the $\mathrm{CRC}$ contract administrators will initiate quarterly user group meetings as a means to monitor contractor performance, improve customer service, and provide a technical forum for users of the services.

\subsubsection{Legato enterprise agreement}

On February 10, 1999, the project manager was invited to attend a meeting of LLNL system administrators and Legato representatives to discuss support issues and the feasibility of a facility-wide service subcontract for Legato software. Legato Networker software was currently in use by several organizations throughout the complex. This software provides for the backup and storage of computer data. A reliable backup system was particularly important at this time due to concerns about the year 2000 rollover and its subsequent impact on data reliability.

Following this meeting, the project manager contacted the Legato representative and began a series of discussions for the purpose of determining what kind of an offer the company was willing to make to the LLNL. It was determined that the enterprise would 
provide unlimited access to a twelve product suite, support services, training, and maintenance updates.

Due to the distributed nature of LLNL procurements, it is difficult to obtain the metrics necessary to successfully negotiate a volume purchase or enterprise license agreement. With no established mechanism whereby this kind of usage and/or procurement information can be easily obtained, the project manager began the arduous process of soliciting usage and interest information from the user base. This was done through electronic mail to various LLNL user groups and NewsOnline, a lab-wide electronic newsletter.

Users interested in participating in a Legato enterprise agreement responded to the project manager who began compiling the necessary data to initiate the procurement. The project manager also met with existing users of the software to solicit interest in participating in a Lab-wide agreement and with SND management to elicit support for the project.

On April 21, 1999, the project manager met with the Legato representative to review interest data and terms of the enterprise agreement. To date the project had not received the kind of interest necessary to move forward with the procurement. The project manager recommended vendor participation in order to obtain a better response to the proposal. On April 28, 1999, the project manager together with LLNL managers representing the two largest Legato user groups met with Legato representatives to map out a strategy for increasing Networker software usage. Also in attendance at this meeting was a representative from the Procurement $\&$ Materiel department. It was determined at the April 28 meeting that license and support costs would need to be lowered or 
compensation given to the largest user groups in order for the project to become successful.

On May 5, 1999, the project manager met with the Procurement \& Materiel contract representative to go over the final proposal from Legato and review the statement of services for the contract award. On May 7, 1999, the CRC sponsored a Legato seminar and product review for Legato users and potential users. The seminar received a good turnout and positive response to the product and the enterprise agreement (see Appendix O, Legato Enterprise License for LLNL). On June 8, 1999, the project manager and Procurement \& Materiel contract representative met with the Legato representative to review the final terms and conditions of the agreement.

On June 12, 1999, the project manager requested institutional funding for the license portion of the agreement with support being paid by users over the three-year term of the agreement. On July 1, 1999, the project manager received institutional funding for the license portion of the agreement in the amount of $\$ 500 \mathrm{~K}$. On July 15 , 1999, the three-year enterprise agreement was signed and on July 29, 1999, a rollout meeting was held for all LLNL users to review the terms of the contract and provide other useful information about products and services.

On September 15, 1999, after receiving complaints from users about delays in obtaining support services, the project manager arranged for a meeting at Legato headquarters in Palo Alto, California. Four LLNL employees met with Legato support services management to discuss various issues. It was determined from this meeting that LLNL calls for service would be handled by a single point of contact and also receive second, rather than first level access to Legato technical support personnel. 
On November 3, 1999, the first Legato User Group meeting took place for the purpose of resolving user issues and providing information about training for new product users. At the second Legato User Group meeting on January 19, 2000, a Legato development engineer provided training on installing Networker on Unix systems. Since the inception of the contract, Legato usage has risen from 2000 to over 3600 systems. This increase has impacted the $\mathrm{CRC}$ in several ways bringing more customers into the facility and also generating more high-level management interest in the activities of the facility.

\subsubsection{Oracle enterprise agreement}

At the end of June 1998, an LLNL five-year volume purchase agreement with Oracle Corporation expired. This volume agreement offered the LLNL user community significant discounts on software licenses, maintenance, technical support, consultation, and training services. The subcontract was administered by the CRC. Prior to the expiration of the contract, the CRC manager had tried to negotiate a similar kind of agreement with Oracle, but was informed that the corporation no longer offered volume procurements outside of its Government Services Agreement. For the LLNL, procurements under the Government Services Agreement meant at least a 50 percent increase in the cost of Oracle products and services. Oracle was willing to propose an enterprise agreement to the LLNL to replace the expired volume purchase, but the costs for this kind of agreement was beyond the scope of the LLNL at the time.

On March 2, 1999, the project manager was invited to attend a meeting between members of the LLNL Administrative Information Services department and Oracle representatives. The Administrative Information Services group had initiated its own 
enterprise agreement several years earlier, effectively splitting themselves off from the volume purchase agreement. The expiration of this separate agreement was now imminent and it was clear that there were some discrepancies in usage terminology between the LLNL group and Oracle. Because the Administrative Information Services organization could not fund a continuation of its agreement under the usage terms, it became necessary for the larger institution to get involved in establishing a site-wide enterprise. It was also clear that an institutional agreement would result in significant savings for the LLNL over the term of the subcontract.

On March 10, 1999, a series of meetings began to determine the products that would be included in the enterprise, the current and potential usage of each of these products, and the support level required to service the LLNL user community. A process for soliciting interest in and funding for the enterprise was also discussed. These meetings took place on March 16, April 2, and May 4, 1999. On July 27, 1999, the project manager met with the Administrative Information Services group, Procurement \& Materiel contract representatives, and Oracle team to review the final enterprise proposal.

The next step was to obtain user support. Responsibility for obtaining commitment from LLNL operations and services would be handled by the AIS team, while responsibility for getting commitment from the programs would be handled by the CRC. Institutional funding would be solicited based on the commitments received. Unfortunately, the programs were not forthcoming with commitments to the enterprise and so institutional funding was not approved. Since CRC personnel were responsible for obtaining this commitment, Administrative Information Services and Oracle personnel blamed them for preventing a final execution of the subcontract. 
On October 5, 1999, Administrative Information Services called a meeting with SND management to solicit support for trying again to implement an Oracle enterprise agreement. On October 21, 1999, the project manager met with the Administrative Information Services group for the purpose of revitalizing the original Oracle proposal. Following this meeting a series of individual program meetings took place to obtain commitments for funding support. Administrative Information Services had already received institutional support for its portion of the agreement, which turned out to be nearly 85 percent of the total LLNL usage. On November 15, 1999, the Oracle enterprise agreement was signed.

On November 17, 1999 the project manager presented the contents of the agreement to the Desktop Advisory Group and on December 14, 1999, the contract terms and conditions were presented to a Lab-wide population (see Appendix P, Oracle Network License). The CRC will continue to administer the Oracle agreement and will be responsible for collecting program funding each year of the five-year agreement.

Enterprise agreements represent a new type of agreement to the CRC and the LLNL. Enterprise agreements, like Oracle and Legato, receive institutional funding for the license portion of the agreement, and user (participant) funding maintenance and support. This represents a dilemma to the $\mathrm{CRC}$ because its fee-for-service mechanism cannot be applied to the institution to pay for the contract administration work effort. The project manager continues to work with Budget \& Finance through the SND Resource Manager to develop a new funding model. 


\subsection{Computer Acquisition Specialist (CAS) program}

The third component to the senior project is perhaps the most difficult to achieve as it relates to a change in Laboratory culture within each programmatic organization. The goal of this subproject was to convert the decentralized computing-related procurement function into one that is centrally dispatched in various locations, yet forming a single department that reports to a manager at a central location (Blanding, 1991, p. 60).

Under the SND, computer support personnel are located within each LLNL directorate or program. These Computer Support Units are managed by a Client Liaison who reports to an SND manager. Having a computer acquisition specialist assigned to work within each computer support unit provides the larger organization with a link between equipment purchases and technical support. The computer acquisition specialist also provides purchasing and technology consultation to directorate personnel, thereby relieving computer support personnel from the need to provide this service. The computer acquisition specialist provides an important link to the computer support unit on the current needs and wants of program personnel. The computer support unit team members provide the procurement specialist with technical expertise and guidance, thereby improving to his or her technical skills. The computer acquisition specialist works closely with the support group to streamline the order-to-equipment installation process, ensuring equipment compatibility and standards, and providing purchasing metrics to the larger organization (see Appendix Q, Computer Acquisition Specialist).

The effort to promote this concept involved contact with the client liaison of each Computer Support Unit to gain advocacy for the plan with department and/or program management. After meeting with each support unit manager, if continued effort was 
warranted, the project manager met with program management for the purpose of describing, promoting, and implementing the program.

The original intention of the project manager was to promote having the computer acquisition specialist assigned to the program on a matrix basis from the CRC. Under this plan the $\mathrm{CRC}$ would become the training area for new and/or inexperienced procurement specialists, with the CRC manager providing supervision, training and administrative oversight. Another advantage for the computer acquisition specialist would be performance recognition for the value of the work performed. This kind of recognition is not often provided in the distributed TRR environment. Additionally, all computer acquisition specialist staff would be appraised and ranked within a group of his or her peers, providing a more equitable appraisal and ranking process for individuals performing the TRR function.

As each contact was made, the project manager received some interest and some resistance, but little commitment to change the status quo. A large part of the resistance came from departments that had no intention of adopting the matrix concept.

Additionally, there was considerable mistrust about the motive of the program because it was associated with the $\mathrm{CRC}$ and, by association, its value-added fee assessment, which has been problematic for some groups.

Following is a chronology of each contact made and the results to date from each:

\section{Engineering}

The project manager met with the Client Liaison for Engineering in February 1999. Even though this client liaison found merit in the Computer Acquisition Specialist plan, he made it clear that Engineering preferred to use the CRC facility for its computing- 
related purchases. It should be stated that the CRC is currently housed in an Engineering facility and receives technical support from the Engineering computer support unit, and facility support from the Engineering Directorate. Engineering has also historically been an advocate and supporter of the CRC mission and continues to provide the $\mathrm{CRC}$ with a large portion of its business.

Even though the Engineering department did not favor having a computer acquisition specialist work within its support area, the project manager feels that a stated desire to continue using the $\mathrm{CRC}$ for computing-related purchases meets the objective of streamlining computer-related procurement practices.

\section{Lasers}

On May 10, 1999, at the advice of the Lasers client liaison, the project manager met with a Lasers program manager to discuss the computer acquisition specialist program. This manager was very supportive of the idea and saw great merit in its application for the Lasers Directorate. However, the manager felt that it was important to take a gradual approach to any kind of implementation. On May 17, 1999, the project manager met with the Lasers client liaison and her staff. It was clear that this computer support unit was already using the services of the $\mathrm{CRC}$ and even though they could see value in a dedicated procurement specialist for their organization, for reasons having to do with funding, they felt this would be difficult if not impossible to achieve.

On July 14, 1999, the Lasers directorate was hit with the shutdown of one of its major programs. This shutdown meant that many LLNL employees needed to be placed into positions in other areas of the Laboratory. TRRs were part of this group of employees now seeking employment elsewhere. Additionally, in September 1999, the 
Lasers Directorate began cutting back on staff assigned to one of its largest projects. This second cutback put any plans to add a computer acquisition specialist to the Lasers computer support unit on hold.

\section{NAI and Computations}

On March 9, 1999, the project manager met with the client liaison to the NAI and Computations directorates together with the department's TRR manager and several members of the buying staff. It was clear that neither the client liaison, nor the project manager were adequately prepared for the animosity expressed by the TRRs during this meeting. It appeared that these individuals felt threatened by what they viewed as $\mathrm{SND} / \mathrm{CRC}$ interference into their work activity. Following this rather disastrous meeting, the NAI/Computations client liaison, who was also new to his assignment, understandably backed away from the program.

Later on the project manager pursued a one-on-one meeting with the TRR manager in an attempt to convince her of the value of assigning one of her existing buyers as a computer acquisition specialist in support of the computer support unit. The idea was that there is still merit in the program even if the specialist is not provided on a matrix from the SND/CRC. Even though this meeting was conducted on more amiable terms, the TRR manager was still not convinced of the merit of having a computer acquisition specialist in her work unit.

Interestingly, the NAI/Computations TRR manager contacted the project manager in July 1999, expressing interest in obtaining information about how the CRC had been able to reclassify its TRRs. However, there was still no interest in adopting the computer acquisition specialist concept. 
Shortly after meetings with the NAI, Computations, and Lasers management, the project manager ran into difficulty getting an audience for presenting the program. The security issues currently impacting the LLNL and specifically the SND were completely absorbing everyone's time and energy and made it extremely difficult, it not impossible, to gain entrance into already overwhelmed work schedules. For the next several months the project was on hold.

\section{Defense Nuclear Technologies}

On October 21, 1999, the project manager met with the client liaison of the Defense Nuclear Technologies directorate to explain the computer acquisition specialist plan and discern if there might be interest in pursuing a similar plan for the Defense Nuclear Technologies computer support unit. It was made clear to the project manager that due to the security nature of the work performed by various sections of the directorate, there was little or no crossover of effort. Due to this lack of cooperation or even association among the different sections of Defense Nuclear Technologies, there would be little advantage to or even possibility of providing a centralized computer acquisition specialist program for this directorate. The current Defense Nuclear Technologies TRR structure matches the separate and divided nature of the directorate.

\section{Energy}

On November 11, 1999, the project manager met with the client liaison of the Energy directorate. This individual expressed great interest in the computer acquisition specialist program and, in fact, had recently enjoyed the benefits of a dedicated person in her support unit. However, due to personnel conflicts with this particular individual, she had been transferred to another area of the directorate leaving the Energy computer 
support unit without a TRR specialist. Even though the client liaison would find great value in having another dedicated computer acquisition specialist assigned to her unit, she would not want to have the previous occupant of this position returned to her area. Moving a new computer acquisition specialist in from the $\mathrm{CRC}$ would require additional funding, which at this time the directorate did not have. The project manager was encouraged to keep in touch with the client liaison for possible changes in funding or staffing in the Energy directorate.

Several weeks after this meeting, the Energy client liaison contacted the project manager to provide her with statistics in support of the computer acquisition specialist program. These statistics indicated that when the Energy computer support unit lost its dedicated TRR, call demand on its technical support staff for computing-related acquisitions increased by 90 percent.

\section{Chemistry}

On January 7, 2000, the project manager met with the Chemistry client liaison. This individual expressed great enthusiasm and support for the computer acquisition specialist program. He made arrangements for the project manager to meet with the Chemistry operations manager and senior administrator on January 12, 2000, to discuss how the computer specialist plan might be implemented within the directorate. During this meeting it was made known that even though this department was interested in participating in the project, the TRR selected as the best candidate for this assignment would not be transferred to the SND. Instead, this individual would remain assigned to Chemistry on a matrix basis from Engineering. The CRC would provide training and/or mentoring only. 
From this feedback it became clear to the project manager that in order for the computer acquisition specialist program to work well for areas that did not want to matrix an SND employee, a separate training and/or mentoring program would have to be designed. This will be one of the ongoing projects for the project manager in the months following the senior project.

On January 27, 2000, the Chemistry client liaison notified the project manager that a higher level meeting had taken place within the directorate to discuss the computer acquisition specialist program. There was agreement at that meeting that the program was a good idea and one that should not be discarded, even though current procurement activity did not warrant a change at this time. The project manager was asked to contact the Chemistry client liaison after October 1, 2000, to see if implementation of the computer acquisition specialist program would be more feasible at this time.

\section{Business Operations}

On January 12,2000 , the project manager met with the Business Operations client liaison to discuss the computer acquisition specialist plan and how it might work in the business operations environment. Many of the issues facing other directorates do not impact business operations because of its management structure. However, the client liaison offered to pass on the computer acquisition specialist information to her department operations manager. On January 31, 2000, the project manager contacted this individual in an effort to set up an appointment to discuss the computer acquisition specialist program. The operations manager said that he would not be able to help the project manager and referred her to the Procurement \& Materiel group leader in charge of the LLNL TRR program. 
On February 18, 2000, the project manager met with the Procurement \& Materiel group leader to discuss possible implementation of the computer acquisition specialist program in Business Operations. It became readily apparent that due to the internal structure of Business Operations, this department really had no need to adopt the computer specialist program. One of the most important advantages to the computer acquisition specialist program is the link between the computer support unit staff and the procurement specialist. This linkage makes it possible for the technical staff to be informed about, have input to and gain control over the computer technology being purchased. For most of the computer support units this is a critical problem, however, for Business Operations, it is not an issue because department management requires that any computer system be pre-approved before purchase.

Additionally, Business Operations management specifies standard computer configurations for department staff and takes advantage of volume purchase discounts by purchasing computers in bulk. For example, the department required that the majority of its staff move from the Macintosh to the personal computer platform and in concert with the Business Operations computer support unit orchestrated a volume buy of Hewlett Packard machines. The Business Operations computer support unit coordinated the rollout, training, and set up requirements throughout the department. This kind of coordination between department personnel, technical support personnel, and the TRR epitomizes one of the most important concepts of the computer acquisition specialist program. 


\section{Earth \& Environmental Science}

On January 18,2000 , the project manager met with the client liaison for the Earth \& Environmental Sciences computer support unit, together with a former TRR from the CRC. Apparently, the former CRC TRR had been performing a computer specialist function for the directorate since joining the group as a technician several months ago. Seeing the great advantage of having a computer acquisition specialist working within his organization, this computer support manager, together with directorate personnel had informally used the services of this TRR for providing the computer specialist function. However, since this individual was not hired as a TRR, a mechanism for employing a full-time computer acquisition specialist was greatly desired.

Funding for the computer acquisition specialist program appeared to be the greatest obstacle. Similar to the Chemistry experience, this client liaison felt that the directorate would not accept a matrix of an SND/CRC TRR. He felt they would prefer to have an existing TRR receive specialized training and/or mentoring through the CRC. The project manager was told that the client liaison would get in touch with the Earth \& Environmental Sciences operations manager and others involved with the directorate's TRR program, and respond with a convenient time for a return visit.

After receiving no response for several weeks, despite several attempts at making contact, the project manager learned that the client liaison was leaving the LLNL for another position. Upon hearing this news, the project manager tried once again and this time received a voicemail message stating that the client liaison had met with the Earth \& Environmental Sciences operations manager and the project manager should contact this individual. 
The project manager has since learned there is a major reorganization taking place whereby the Earth \& Environmental Sciences and Energy directorates will merge. The transition to accomplish this merger will take several months and will not be completed until calendar year, 2001.

On March 1, 2000, the project manager met with the operations manager of the Earth \& Environmental Sciences directorate. This meeting was quite positive and left the project manager with the impression that once the two directorates are combined, the computer acquisition specialist program would be seriously considered as part of the restructuring process. The project manager will contact the Earth \& Environmental Sciences operation manager in June 2000.

\section{Site Operations}

On January 28, 2000, the project manager met with the client liaison for the Site Operations computer support unit. This individual liked the computer acquisition specialist concept, but also expressed doubt in being able to coordinate the three distinct site operations divisions into one program. Apparently, much like Defense Nuclear Technologies each Site Operations division works autonomously and employs its own TRR. The client liaison will contact his operations manager and get back to the project manager about any interest.

On February 8, the project manager reminded the Site Operations client liaison about the meeting and was told he would get back soon with a meeting time and place. When the project manager received no response, she sent an email message on February 23, again reminding the client liaison about the meeting. To date the project manager has not been able to meet with the Site Operations manager. 


\section{Biology \& Biotechnology Research Program and the Directors Office}

Due to the overwhelming work schedules and activities of the client liaison for these areas, multiple efforts to meet to discuss the computer acquisition specialist program have not been successful. New management and oversight for these areas has recently been established. Once things have settled down, the project manager will contact the new management to set up a convenient meeting time to discuss the computer specialist program.

Physics

The Physics directorate is the working model for the computer acquisition specialist program. In December 1998, a computer acquisition specialist was hired by the CRC manager and assigned to work in Physics under the work direction of the computer support unit's client liaison. The CRC manager provides supervision and administrative oversight to this TRR. The TRR attends CRC staff meetings and has access to CRC information, training, and tools. This partnership has been successful. However, it should be noted that its success was based on a commitment from and internal reorganization of the Physics Directorate.

It is this kind of cultural shifting that is required before the computer acquisition specialist program can be successfully implemented. During the time of the senior project the seeds were planted and for some organizations they may produce successful computer acquisition specialists programs. Certainly the Earth \& Environmental Sciences, Energy, and Chemistry directorates have expressed the greatest interest in the program. The NAI, Computations and Site Operations departments may also become participants, while Lasers and Engineering will most likely continue using the CRC for their computing- 
related needs. Adoption of the program by Defense Nuclear Technologies, Biology \& Biotechnology Research, Business Operations, and the Director's Office is not anticipated. 


\subsection{Historical analysis: evaluation results}

\subsection{Restatement of purpose and objectives}

The project will alter policy and practice of the CRC internal organization. New services will be offered, giving Laboratory personnel more reason to have contact with the facility. Implementation of the project will provide value to both the internal and external organization in helping to streamline the computing-related procurement process. Institutional dollars will be saved by lowering total cost of ownership through site licensing, enterprise and volume purchase agreements for the acquisition of software, hardware, and other computing-related services.

\subsection{Evaluation of project objectives}

\subsubsection{Objective One}

From April 1999 through March 2000, increase the customer base of the Computing Resource Center by 10 percent by implementing internal-to-the organization changes and value-added customer services.

The percentage increase in the customer base will be determined by comparing monthly sales during the evaluation period (April 1999 through March 2000) with sales from the period April 1998 through March 1999. An additional measure will be a comparison of services subcontract enrollments at the beginning and end of the evaluation period.

\subsubsection{Objective Two}

From February 1999 through March 2000, improve CRC customer service ratings by 25 percent by implementing internal-to-the organization changes and value-added customer services. 
The following Gantt charts compare the start and finish times for the project plan task schedule (gray dot) with the actual task schedule (red diagonal).

\section{Internal Reorganization}

\begin{tabular}{|l|c|c|c|c|c|c|c|c|c|c|c|c|c|}
\hline Objective & $\begin{array}{c}\text { Apr- } \\
99\end{array}$ & $\begin{array}{c}\text { May- } \\
99\end{array}$ & $\begin{array}{c}\text { Jun- } \\
99\end{array}$ & Jul-99 & $\begin{array}{c}\text { Aug- } \\
99\end{array}$ & $\begin{array}{c}\text { Sep- } \\
99\end{array}$ & $\begin{array}{c}\text { Oct- } \\
99\end{array}$ & $\begin{array}{c}\text { Nov- } \\
99\end{array}$ & $\begin{array}{c}\text { Dec- } \\
99\end{array}$ & $\begin{array}{c}\text { Jan- } \\
00\end{array}$ & $\begin{array}{c}\text { Feb- } \\
00\end{array}$ & $\begin{array}{c}\text { Mar- } \\
00\end{array}$ & $\begin{array}{c}\text { Apr- } \\
00\end{array}$ \\
\hline $\begin{array}{l}\text { Internal Reorganization } \\
\text { - Assessment } \\
\text { - Reorganization process 1 } \\
\text { Reassessment } \\
\text { - Reorganization process 2 }\end{array}$ & & & & & & & & & & & & & \\
& & & & & & & & & & & & & \\
\hline
\end{tabular}

The first internal reorganization process was completed on schedule and some anticipated benefits realized. For example, CRC operating costs were decreased and the internal staff were reclassified and hired as full-time employees of the LLNL. However, less positive outcomes also resulted. Some of these were an increase in internal conflicts among staff members, an imbalance in workload and responsibilities, lack of connection to the customer, database inconsistencies and parts room inventory inaccuracies. All of these factors lead to the need for a reassessment of the first reorganization plan.

Needs and issues were assessed in September and the early part of October 1999, and in late October, the CRC staff implemented modifications to its internal organization structure. The second reorganization has been quite successful leading to an improvement in customer service to the external customer, and perhaps even more important, an improvement in interactions among CRC staff members. Database discrepancies were improved and the parts room inventory inaccuracies were not only identified, but CRC staff members pooled their efforts to reorganize and streamline the parts room activity.

As a by-product of the second reorganization, CRC personnel became more involved on a daily basis with CRC customers. These interactions were increased in large part due to the rotation of the customer counter and help desk functions. Getting closer to 
the customer helped all staff members identify and improve individual customer service skills, and also led to the development of new tools to monitor customer satisfaction.

For example, the Help Desk group worked with the database developer to design a call tracking system. This call tracking database has already been quite useful in targeting and solving customer service issues (see Appendix F, Help Desk Call Tracking Statistics).

\section{CRC Online}

\begin{tabular}{|l|c|c|c|c|c|c|c|c|c|c|c|c|c|}
\hline & $\begin{array}{c}\text { Apr- } \\
99\end{array}$ & $\begin{array}{c}\text { May- } \\
99\end{array}$ & $\begin{array}{c}\text { Jun- } \\
99\end{array}$ & $\begin{array}{c}\text { Jul- } \\
99\end{array}$ & $\begin{array}{c}\text { Aug- } \\
99\end{array}$ & $\begin{array}{c}\text { Sep- } \\
99\end{array}$ & $\begin{array}{c}\text { Oct- } \\
99\end{array}$ & $\begin{array}{c}\text { Nov- } \\
99\end{array}$ & $\begin{array}{c}\text { Dec- } \\
99\end{array}$ & $\begin{array}{c}\text { Jan- } \\
00\end{array}$ & $\begin{array}{c}\text { Feb- } \\
00\end{array}$ & $\begin{array}{c}\text { Mar- } \\
00\end{array}$ & $\begin{array}{c}\text { Apr- } \\
00\end{array}$ \\
\hline \hline $\begin{array}{l}\text { CRC Online } \\
\text { - Focus group } \\
- \text { Research/Planning } \\
\text { - Development } \\
\text { - Beta testing 1 } \\
\text { - Release/distribution }\end{array}$ & & & & & & & & & & & & & \\
\end{tabular}

As evidenced from the Gantt chart, each step of the development and implementation process for CRC Online required more time that originally planned. CRC Online represented a huge effort and could easily have become an entire senior project on its own merit. For the LLNL, CRC Online is the first and only online ordering system of its kind. The extended beta test period gave the web developer time to find and solve problems, receive feedback from testers, and provide database changes that would enhance and facilitate usage. It also gave CRC personnel time to realize and identify areas of personal responsibility for the success of the project. Every Friday morning for a four-week period in late November and December, staff members met to view a portion of CRC Online and see how each change made in the database changed the customer's view of the web site. As each commodity buyer reviewed the cosmetic changes made to his or her product suite, it became visually apparent how that cleanup process changed 
CRC Online. By the time of its official launching, CRC Online had been tried and tested and esteemed by the user community as an excellent dot-com business.

At the present time, users of CRC Online are restricted to ordering only stocked CRC parts. In the next release, CRC Online will enable customers to search and order from the entire CRC database of over 5000 different records. CRC Online has become the place where all CRC services are represented and marketed to the LLNL user community. Most recently, as part of the Desktop Advisory Group desktop standards project, CRC Online will become the mechanism in a pilot program for offering the standard system bundles to the LLNL user community.

CRC Online has already brought many new customers to the Computing Resource Center and coaxed back others who had left for various reasons. It is anticipated that the rollout of the standard personal computer systems will bring an increase to the CRC customer base. Unfortunately, the statistical results of this increased use of CRC Online will not be known in time to present them at the final senior project review.

\section{Product Delivery}

\begin{tabular}{|l|c|c|c|c|c|c|c|c|c|c|c|c|c|}
\hline Objective & $\begin{array}{c}\text { Apr- } \\
99\end{array}$ & $\begin{array}{c}\text { May- } \\
99\end{array}$ & $\begin{array}{c}\text { Jun- } \\
99\end{array}$ & Jul-99 & $\begin{array}{c}\text { Aug- } \\
99\end{array}$ & $\begin{array}{c}\text { Sep- } \\
99\end{array}$ & $\begin{array}{c}\text { Oct- } \\
99\end{array}$ & $\begin{array}{c}\text { Nov- } \\
99\end{array}$ & $\begin{array}{c}\text { Dec- } \\
99\end{array}$ & $\begin{array}{c}\text { Jan- } \\
00\end{array}$ & $\begin{array}{c}\text { Feb- } \\
00\end{array}$ & $\begin{array}{c}\text { Mar- } \\
00\end{array}$ & $\begin{array}{c}\text { Apr- } \\
00\end{array}$ \\
\hline \hline $\begin{array}{l}\text { Product Delivery } \\
\text { - Meet w/Transportation Dept } \\
\text { - Meet w/Shipping \& Receiving } \\
\text { - Implement delivery option }\end{array}$ & & & & & & & & & & & & & \\
\end{tabular}

Implementing product delivery for the $\mathrm{CRC}$ is a primary goal of the project manager. However, the difficulties associated with realizing this goal have been substantial as evidenced in the Gantt chart. After realizing that implementation of a delivery program with CRC personnel and equipment would be cost prohibitive, the project manager sought other methods for obtaining the service. A meeting in August 
1999 with the Transportation group went well, but its delivery rates were too high, over $\$ 100$ per hour. At these rates, the CRC would not be able to offer delivery free-of-charge to its customers and for most customers a $\$ 100$ delivery fee would be out of the question.

The project manager also contacted Shipping \& Receiving about potential delivery service. After several false starts and stops and significant delays in negotiating an arrangement for a more cost effective delivery service through Shipping \& Receiving, the project manager met with a positive outcome on March 1, 2000. At this March 1 meeting, the project manager learned that Shipping \& Receiving was reevaluating the need to find work for its afternoon work shift. The Shipping \& Receiving manager saw the CRC delivery business as a positive solution to the problem. On March 7, 2000, the project manager met with the Materiel Distribution division leader, Shipping \& Receiving manager, and other staff members. This meeting was positive. A memorandum of understanding between the SND and Materiel Distribution has been approved and a pilot delivery program will begin in mid-April. During the term of the pilot, only CRC Online orders will be delivered.

\section{Software and Hardware Contracts}

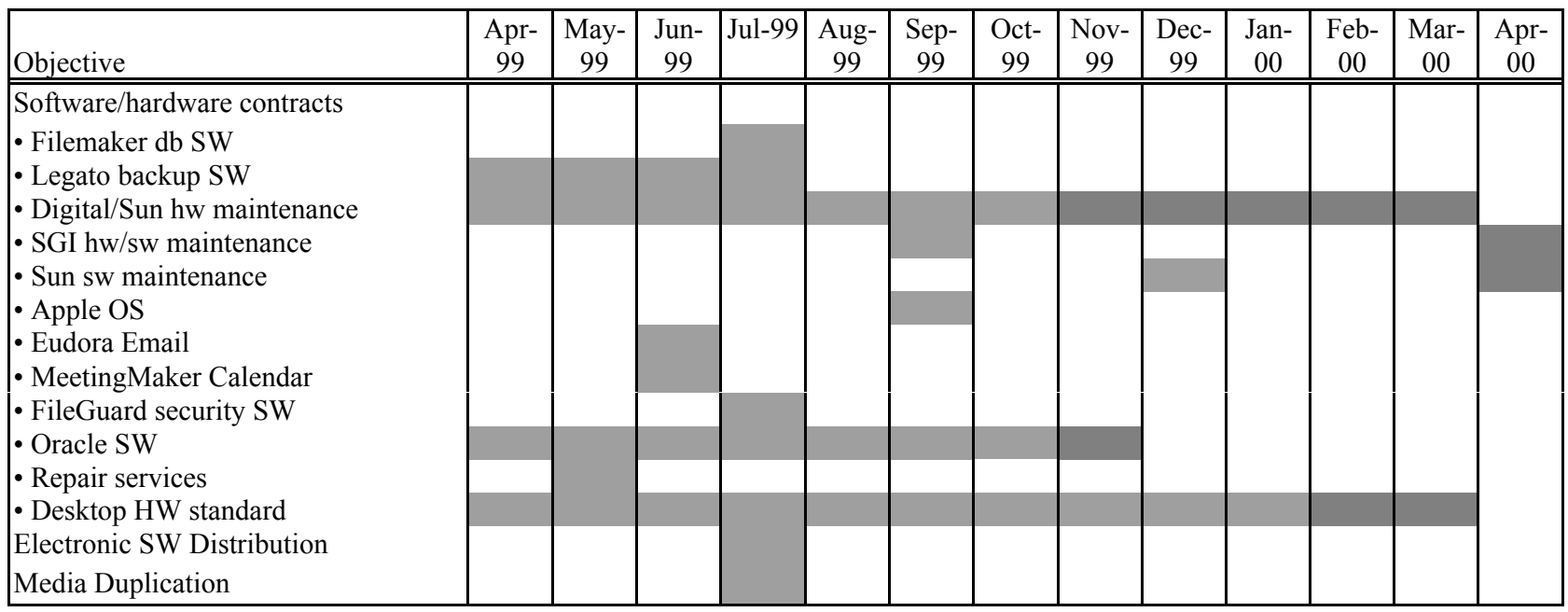


The process of soliciting proposals for a continuation of hardware maintenance services was long and difficult. In order to maintain continuous coverage for enrolled systems, the terms of the existing contracts were extended five different times.

Negotiation and implementation of the Oracle and Legato enterprise agreements was also extensive and fraught with difficulties. However, the implementation of all these agreements and others has provided benefits to the LLNL with significant cost savings, as well as standardization of database development through Oracle and data backup and storage through Legato.

The ongoing work of the Desktop Advisory Group toward the implementation of computing standards for the LLNL has been periodically started and stopped for many reasons. Some of these starts and stops came as a result of political and/or cultural concerns, while others were a result of forces outside the LLNL like the government stand down in April 1999.

More recently, the standards work has taken a new turn. The project manager, as a part of the standards work group, suggested using existing CRC services in a pilot program to manage and deliver pre-configured computers to the LLNL user community. At first this suggestion was rejected, but later reconsidered as a workable solution. It now appears that initially CRC Online will be the vehicle to market and deliver the personal computer and Macintosh systems to the user community.

As part of the vendor liaison work, the project manager and CRC staff work closely with the SND SouRCe (Systems Research Center) group to ensure that site license and enterprise software is updated and served electronically to the LLNL user community. The SouRCe also helped finance the $\mathrm{CD}$ duplicating equipment purchased by the $\mathrm{CRC}$ in 
July 1999. This duplicating equipment is used to provide site license, enterprise, and volume purchased software to LLNL users.

The ability of the SND to provide electronic software and media distribution has become an integral part of the site licensing, desktop standardization process.

\subsubsection{Objective Three}

Streamline computer-related procurement practices within 15-20 percent of the distributed organizations in the first year (FY99) and 35 percent in the second year (FY00). The project manager has met with each distributed computer support unit to gain advocacy and support of the plan. Meetings with operational personnel have also occurred and will continue in the future.

The out come of objective three will be based on a comparison of the number of organizations implementing the computer acquisition specialist subproject to the number of organizations visited.

\section{Computer Acquisition Specialist Program}

\begin{tabular}{|c|c|c|c|c|c|c|c|c|c|c|c|c|c|}
\hline Objective & $\begin{array}{c}\text { Apr- } \\
99 \\
\end{array}$ & $\begin{array}{l}\text { May- } \\
99 \\
\end{array}$ & $\begin{array}{l}\text { Jun- } \\
99 \\
\end{array}$ & Jul-99 & $\begin{array}{c}\text { Aug- } \\
99 \\
\end{array}$ & $\begin{array}{c}\text { Sep- } \\
99\end{array}$ & $\begin{array}{c}\text { Oct- } \\
99 \\
\end{array}$ & $\begin{array}{c}\text { Nov- } \\
99\end{array}$ & $\begin{array}{c}\text { Dec- } \\
99\end{array}$ & $\begin{array}{c}\text { Jan- } \\
00 \\
\end{array}$ & $\begin{array}{c}\text { Feb- } \\
00 \\
\end{array}$ & $\begin{array}{c}\text { Mar- } \\
00\end{array}$ & $\begin{array}{c}\text { Apr- } \\
00\end{array}$ \\
\hline Program meetings & & & & & & & & & & & & & \\
\hline $\begin{array}{l}\text { - Engineering } \\
\text { - Lasers }\end{array}$ & & & & & & & & & & & & & \\
\hline • NAI & & & & & & & & & & & & & \\
\hline - Chemistry & & & & & & & & & & & & & \\
\hline$\cdot$ DNT & & & & & & & & & & & & & \\
\hline - Business OPS & & & & & & & & & & & & & \\
\hline • Site OPS & & & & & & & & & & & & & \\
\hline - Earth \& Environmental & & & & & & & & & & & & & \\
\hline $\begin{array}{l}\text { - Director's Office/BBRP } \\
\text { - Eneroy }\end{array}$ & & & & & & & & & & & & & \\
\hline
\end{tabular}

Results from the effort toward implementing a computer acquisition specialist program have been quite disappointing. The lack of positive results in this area could be due to many factors. First, implementation of a computer acquisition specialist program 
requires organizational change, a change over which the project manager and the computer support unit manager have no control. Second, reaching the right audience has been problematic. Most often the computer support unit manager, the project manager's conduit to program personnel, had no access to the appropriate contact(s). In these cases a more formal access to these individuals through introduction or expressed advocacy by SND management could have resulted in more positive outcomes. It is interesting to note that when the right connection was made as in the case of the Earth \& Environmental Sciences, Energy, and Chemistry directorates, the computer acquisition specialist program received a positive reaction that may lead to its future adoption in these areas.

Organizational issues beyond the control or scope of the project manager also occurred that impacted her ability to promote the computer acquisition specialist program. The first of these events occurred in April 1999 when the LLNL was forced into a stand down of all business and programmatic activity due to security-related issues. The stand down alone would have been a minor difficulty to the process of implementing the program, but the security issues raised had far-reaching effects that still permeate every LLNL activity. The security related issues resulted in a lack of support from SND management for the program. This lack of support, even interest, was in no way malicious, it was simply a manifestation of needing to focus time and energy on other more critical areas.

Even though the computer acquisition specialist program has not achieved its goal of reaching 15-20 percent of the distributed organizations in the first year (FY99) and 35 percent in the second year (FY00), the seeds of the program have been planted. The project manager feels quite certain that the Chemistry, Earth \& Environment Sciences, 
and Energy directorates will implement a form of the computer specialist program during fiscal year 2001 .

For other areas the computer acquisition specialist program does not seem like a good fit, this is particularly true for Business Operations and Defense Nuclear Technologies. There may be hope in convincing the NAI, Computations, and Site Operations organizations of the value of the program once the appropriate controlling individual can be reached. The Engineering directorate already uses the CRC as an exclusive source for its computing-related procurements as does the Lasers directorate. Both of these, along with Physics are considered a successful part of streamlining computer-related procurement practices at the LLNL.

\subsection{Evaluation of project budget}

The budget for the project is recovered by a fee-for-service rate assessed to the value of the customer's total order. The original project budget showed a recovery rate schedule of 8 percent on a total order greater than $\$ 2500$, a 14 percent rate on a total order greater than $\$ 200$ and less than $\$ 2500$, and a 25 percent rate on a total order less than $\$ 200$. The three-tier rate turned out to be confusing for customers and resource managers and the $\mathrm{CRC}$ received many complaints. The project manager after many discussions on the subject with the SND resource manager and her discussions on the issue with LLNL Budget \& Finance finally received permission to move the CRC to a flat rate of 10 percent. This new rate became effective January 1, 2000.

A comparison of the projected plan budget and the actual plan budget follows: 
Projected Project Plan Budget

(Apr 1999 thru Mar 2000)

\begin{tabular}{|c|c|c|c|c|c|c|c|c|c|c|c|c|c|}
\hline Category & Apr-99 & May-99 & Jun-99 & Jul-99 & Aug-99 & Sep-99 & Oct-99 & Nov-99 & Dec-99 & Jan-00 & Feb-00 & Mar-00 & Total \\
\hline Labor & 77903 & 77903 & 77903 & 77903 & 77903 & 77903 & 77903 & 77903 & 77903 & 77903 & 77903 & 77903 & 934836 \\
\hline Training & 2200 & 2200 & 2200 & 2200 & 2200 & 2200 & 2200 & 2200 & 2200 & 2200 & 2200 & 2200 & 26400 \\
\hline Equipment & 11500 & 0 & 0 & 0 & 0 & 0 & 0 & 0 & 0 & 0 & 0 & 0 & 11500 \\
\hline Space & 9780 & 9780 & 9780 & 9780 & 9780 & 9780 & 9780 & 9780 & 9780 & 9780 & 9780 & 9780 & 117360 \\
\hline Supplies & 250 & 250 & 250 & 250 & 250 & 250 & 250 & 250 & 250 & 250 & 250 & 250 & 3000 \\
\hline Technical support & 1000 & 1000 & 1000 & 1000 & 1000 & 1000 & 1000 & 1000 & 1000 & 1000 & 1000 & 1000 & 12000 \\
\hline \multirow[t]{2}{*}{ Institutional taxes } & 5250 & 5250 & 5250 & 5250 & 5250 & 5250 & 5250 & 5250 & 5250 & 5250 & 5250 & 5250 & 63000 \\
\hline & $\$ 107,883$ & $\$ 96,383$ & $\$ 96,383$ & $\$ 96,383$ & $\$ 96,383$ & $\$ 96,383$ & $\$ 96,383$ & $\$ 96,383$ & $\$ 96,383$ & $\$ 96,383$ & $\$ 96,383$ & $\$ 96,383$ & $\$ 1,168,096$ \\
\hline
\end{tabular}

Project Plan Budget Actual

(Apr 1999 thru Mar 2000)

\begin{tabular}{|c|c|c|c|c|c|c|c|c|c|c|c|c|c|}
\hline Category & Apr-99 & May-99 & Jun-99 & Jul-99 & Aug-99 & Sep-99 & Oct-99 & Nov-99 & Dec-99 & Jan-00 & Feb-00 & Mar-00 & Total \\
\hline Labor & 61149 & 84746 & 59371 & 70466 & 63949 & 94506 & 66239 & 61247 & 60256 & 70083 & 63869 & 62058 & 817939 \\
\hline Training & 0 & 0 & 0 & 4478 & 544 & 0 & 0 & 2372 & 0 & 598 & 0 & 0 & 7992 \\
\hline Equipment & 11500 & 0 & 0 & 0 & 0 & 0 & 0 & 0 & 0 & 0 & 0 & 0 & 11500 \\
\hline Space & 8452 & 8456 & 8452 & 13153 & 11344 & 12112 & 11082 & 10597 & 10581 & 13195 & 21514 & 12584 & 141522 \\
\hline Supplies & 150 & 9 & 1911 & 29 & 0 & 0 & 9 & 0 & 0 & 84 & 0 & 0 & 2192 \\
\hline Technical support & 287 & 1123 & 79 & 0 & 0 & 0 & 0 & 0 & 0 & 0 & 0 & 0 & 1489 \\
\hline \multirow[t]{2}{*}{ Institutional taxes } & 781 & 469 & 302 & 1099 & 652 & 1359 & 535 & 658 & 723 & 574 & 635 & 540 & 8327 \\
\hline & $\$ 82,319$ & $\$ 94,803$ & $\$ 70,115$ & $\$ 89,225$ & $\$ 76,489$ & $\$ 107,977$ & $\$ 77,865$ & $\$ 74,874$ & $\$ 71,560$ & $\$ 84,534$ & $\$ 86,018$ & $\$ 75,182$ & $\$ 990,961$ \\
\hline
\end{tabular}

\subsection{Evaluation results}

Meeting objective one required an increase in the $\mathrm{CRC}$ customer base of 10 percent through implementation of the various internal-to-the organization changes and valueadded customer services. The following graphic shows a comparison of CRC total business volume by quarter beginning with the month of March and ending with the month of February. The total comparison shows an increase in business during the period of the senior project of 9.6 percent. 


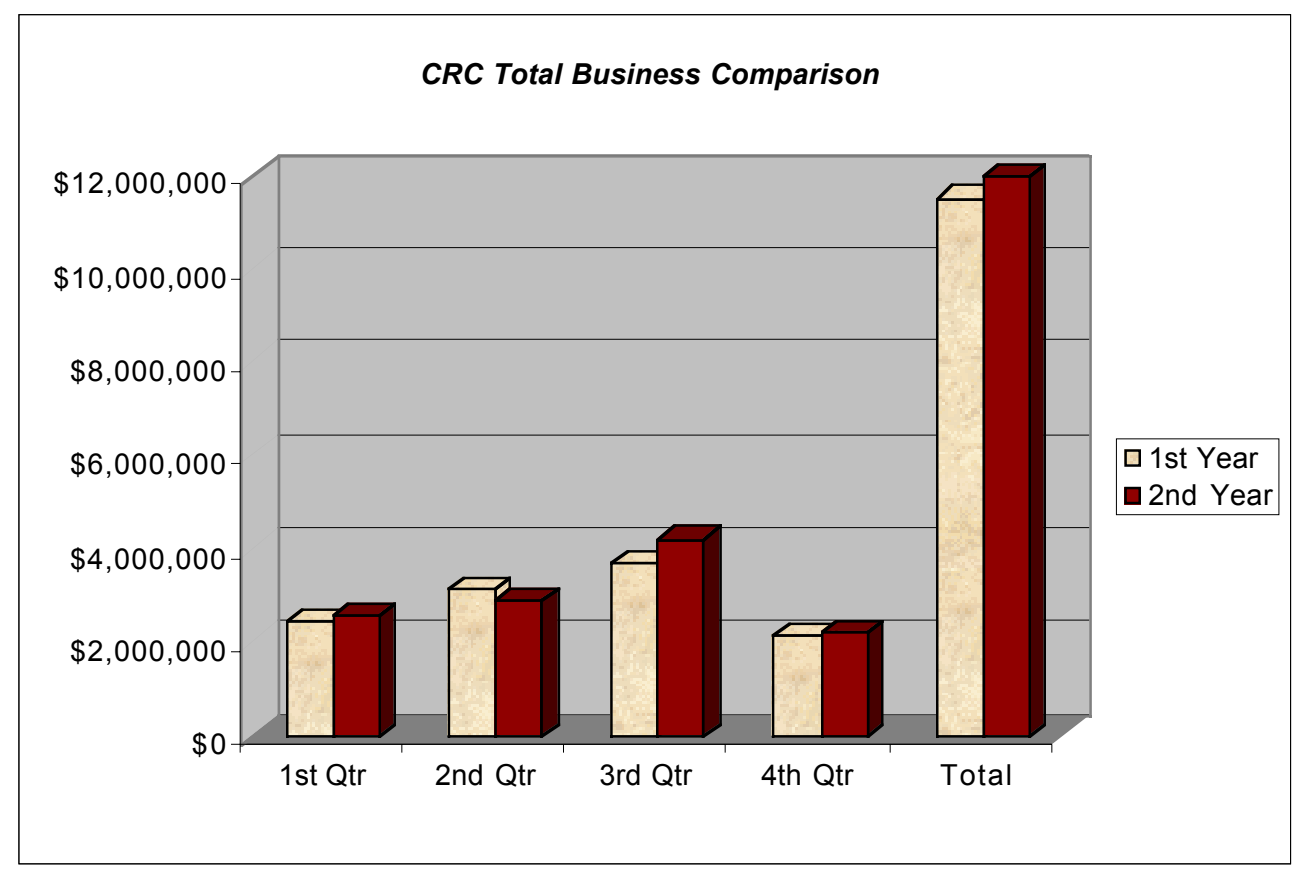

Another indication of increase in the CRC customer base is the comparison of the number of customer enrollments in enterprise and/or service agreements offered through the facility at April 1999 compared to March 2000. Those statistics follow:

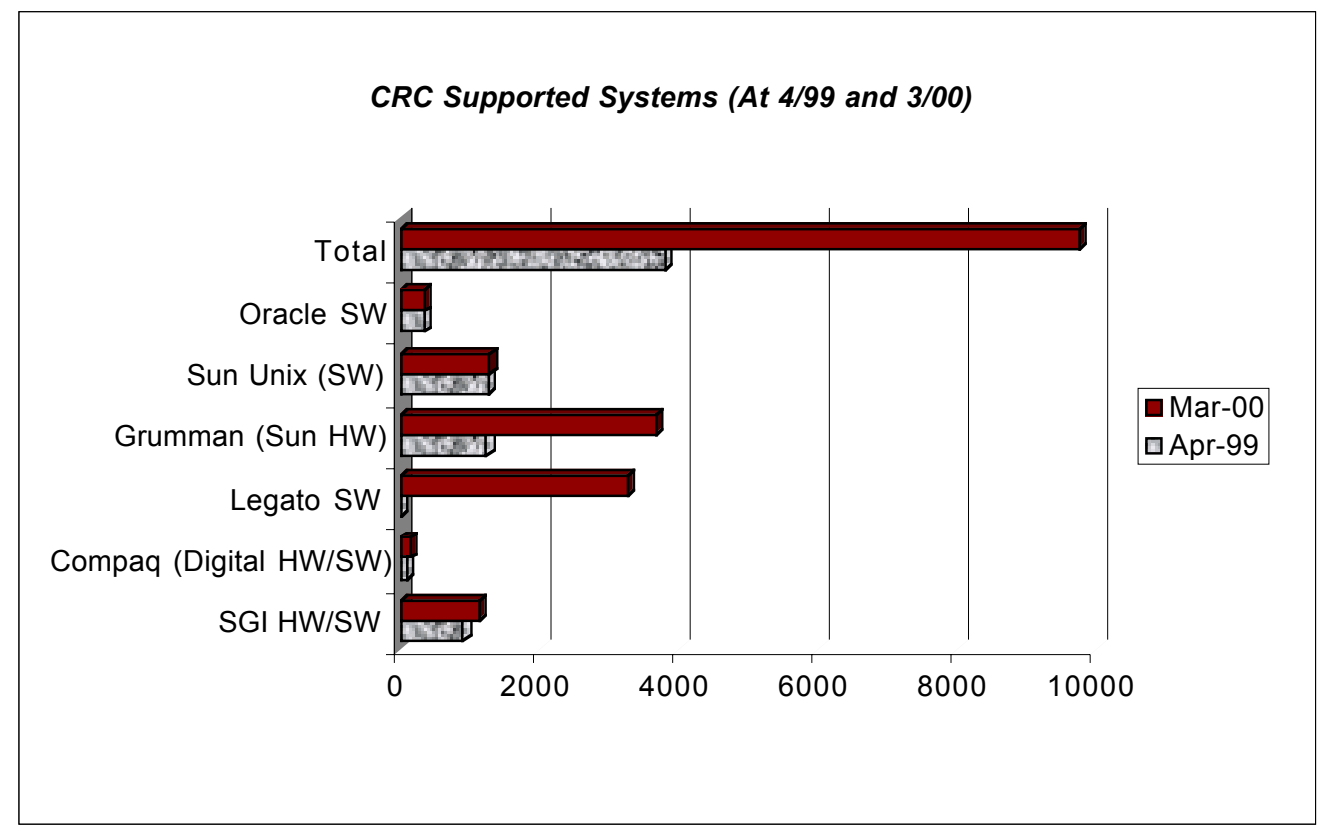


Even though the Computing Resource Center did not quite reach the objective of a 10 percent increase in customer sales activity through the period, it did receive a 39 percent increase in the number of systems enrolled in service agreements administered by the CRC. This positive outcome is indicative of a continuing trend toward a more institutional focus on software and hardware standards at the LLNL.

Meeting objective two requires improvement in CRC customer service ratings by 25 percent. This objective was measured by comparing the results of a CRC customer service survey released in February 1999, with a second survey released in March 2000. The first survey was in a closed question format. According to author, Paul R. Lee-Haley, in the Questionnaire Design Handbook, the closed question is one for which the author has listed two or more alternatives from which the respondent chooses an answer. The type of closed question format used in the first CRC survey was "choice or preference" whereby the subject chose between two or three alternatives (p. 15-16).

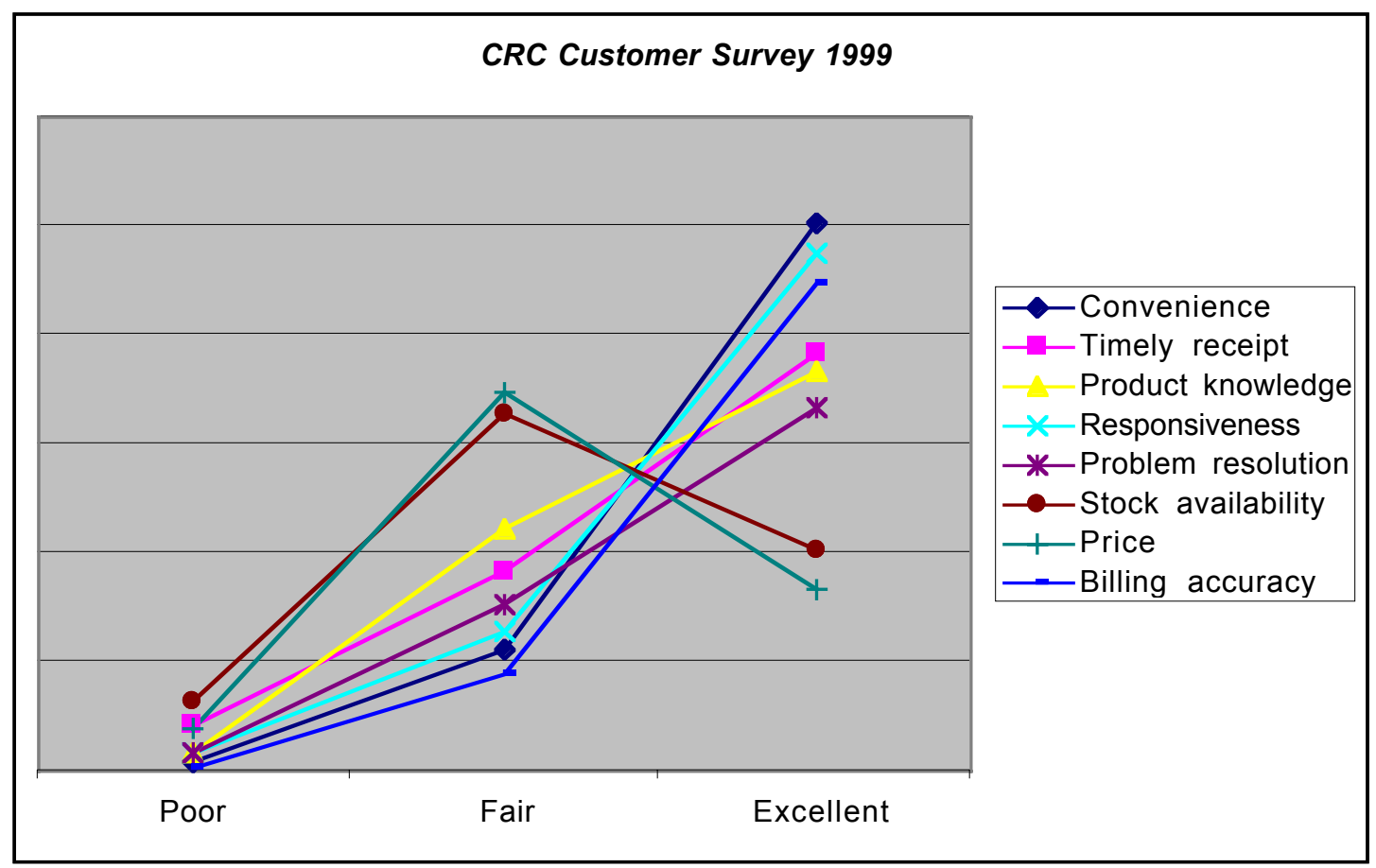


The second CRC survey also used a closed question format, but this time the respondent was given a "rating scale" from which he or she could choose a numerical alternative from 1-10 to reflect the degree of agreement with the statement $(1=$ poor and $10=$ excellent). Both the first and second questionnaires were "brief, simple, and worded specifically with a particular audience in mind" (Lees-Haley, 1980, p. 26). Drafts of the questions and format were reviewed with CRC staff and a select number of CRC customers to obtain feedback on content. Following are the results to date from survey two:

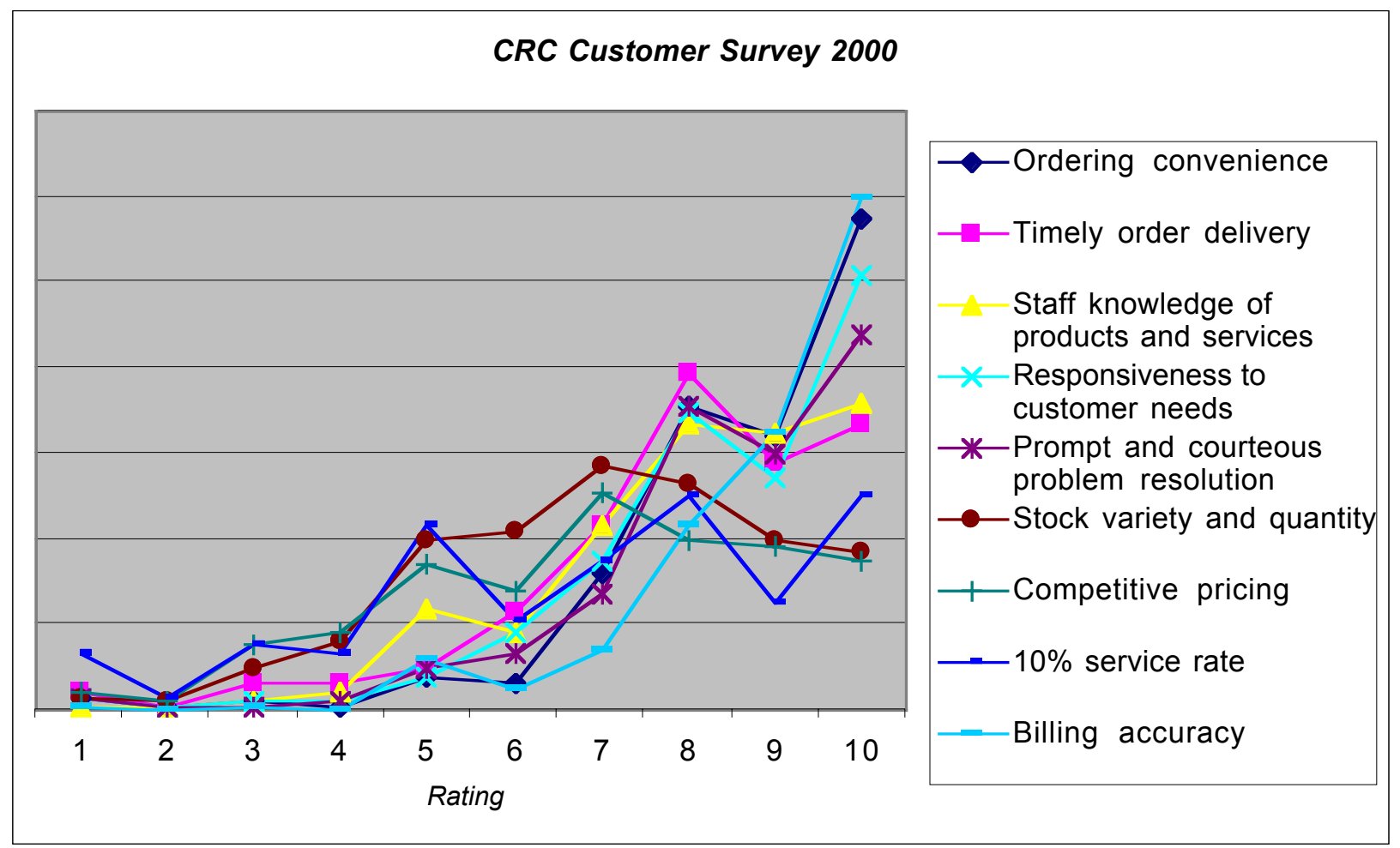

Making a comparison between the results of CRC survey one and survey two was complicated by the new rating scale used in survey two. By combining ratings 1 through 4 and designating them as poor; ratings 5 through 7 as fair, and 8 through 10 as excellent 
show the following percentage increase $(+)$ or decrease (-) in excellent ratings between survey one and survey two:

Ordering convenience:

Timely order delivery:

$-1 \%$

Staff knowledge of products and services:

$6 \%$

Responsiveness to customer needs:

$11 \%$

Prompt and courteous problem resolution

$-5 \%$

Stock variety and quantity

$32 \%$

$27 \%$

Competitive pricing

$35 \%$

Billing accuracy

$2 \%$

Taking an average of these percentages shows an overall increase in the excellent rating of 13.4 percent. It is interesting to note that ordering convenience dropped by 1 percent. With the introduction of CRC Online, the project manager would have assumed an increase in the excellent rating for this category. However, it should also be noted that when asked to indicate a preferred ordering method, $60 \%$ of the CRC customers still preferred to order in person, rather than online. We feel certain that these numbers will change when product delivery is implemented to complement the online ordering method.

Meeting objective three required streamlining computer-related procurement practices within 15-20 percent of the distributed organizations in the first year (FY99) and 35 percent in the second year (FY00). This objective was measured by taking a percentage of the number of organizations adopting a more streamlined computer-related procurement option with the number of organizations visited. Of the twelve SND computer support units, two have chosen to use the CRC facility for computing-related procurements (Engineering and Lasers), while one has adopted the computer acquisition 
specialist program. These statistics result in 25 percent of the distributed organizations adopting a more streamlined procurement practice in FY99. However, this is actually a false positive result because the Physics organization was already utilizing the services of a computer acquisition specialist prior to the beginning of the senior project, and in fact served as the model for the computer acquisition specialist program.

In the second year (FY00), there is a very real chance that three more directorates will adopt the computer acquisition specialist program. These directorates are Earth \& Environmental Science, Energy, and Chemistry. Adoption of the program by these directorates will result in 42 percent of the distributed organizations having streamlined computer-related procurement practices in FY00.

The project manager estimates she spent over 350 hours on completion of this project. 


\subsection{Conclusions and recommendations}

The purpose of the project was to develop, implement, and market value-added services through the Computing Resource Center in an effort to streamline computingrelated procurement processes across the LLNL. The power of the project was in focusing attention on and value of centralizing the delivery of computer related products and services to the institution. The project required a plan and marketing strategy that would drive attention to the facility's value-added offerings and services.

A significant outcome of the project has been the change in the CRC internal organization. The realignment of internal policies and practices, together with additions to its product and service offerings has brought an increased focus to the facility. This movement from a small, fractious organization into one that is still small yet well organized and focused on its mission and goals has been a significant transition.

Indicative of this turnaround was the sharing of information. One-on-one and small group meetings, together with statistics showing work activity was invaluable in gaining support for more equitable workload distribution, and the removal of blame and finger pointing. Sharing monthly reports on sales and operating costs also had a positive impact. Charles Eitel, CEO of Interface, Inc. suggests ten steps or disciplines to be used in helping a company make a change or turnaround. Some of these are employee training and education, waste reduction and quality improvement, weekly meetings on product planning, and communication on everything that can be measured to everyone in the business (p. 1). Sharing information became a key turning point for the internal CRC organization 
The most exciting and positive aspect of the project was the implementation of CRC Online, an electronic business for the procurement of computing-related commodities and services. CRC Online has done more to change the CRC business than any other single value-added service. CRC Online has also become a marketing tool and method of communication to users and non-users of the facility. It has given the organization a presence and prestige within the LLNL community.

The implementation of a customer delivery service to complement CRC Online should serve to further enhance and increase CRC visibility at the LLNL. The fact that the CRC already had a fully developed electronic commerce site also contributed to its being chosen as the pilot for delivering standard computer configurations to the user community. CRC Online will enable users to easily select a standard computer, add it to a shopping cart, and wait for its delivery to the work area.

The pilot program to deliver standard systems will bring heightened awareness of the CRC within the Laboratory community. Historically, elements of promoting the CRC and its services were limited to personal selling, public relations, and sales promotion. With the advent of CRC Online, additional promotional tools of publicity and “interactive communication via some electronic medium, such the Internet" (Zikmund \& d'Amico, 1998, p. 352), were added to the marketing mix. Free publicity for CRC Online occurred when an article about the new service appeared in the January 14, 2000 issue of the Laboratory news publication called Newsline (see Appendix H, CRC Online Articles). The advent of CRC Online, together with efforts to promote and market the services of the CRC store, have raised its visibility and increased its customer base over the period of the senior project. 
The increased positive exposure has led many internal and external customers to express greater satisfaction with the services of the facility. Recently a customer came to the project manager seeking advice about how to open a safety equipment store similar in style and scope to the Computing Resource Center. He expressed great enthusiasm for a one-stop shopping experience that allows him flexibility in making purchasing decisions and saves him time by providing the tools he needs when he needs them.

The most disappointing part of the project was the lack of favorable response to the computer acquisition specialist program. This part of the project was particularly difficult for the project manager forcing her out of her comfort zone and challenging her abilities to sell a foreign concept to a diverse population. So even though results were less positive than anticipated, the process was most beneficial not only to raising the visibility of the Systems \& Network Department, but also to improving the marketing and communication skills of the project manager.

The seeds of the computer acquisition program have been planted and work will continue in the future. New avenues of entrance to the appropriate department and/or program personnel will be sought as will advocacy and promotion for the project from SND management. With these elements in place the project manager feels certain that the program will be adopted by a majority of areas.

The project manager, as the manager of the Computing Resource Center, realized early on the need to promote and increase the value of CRC products and services to the institution, and every year since its inception, the $\mathrm{CRC}$ business has grown. However, to continue that trend while maintaining competitive pricing and low fee-for-service required new thinking and the application of improved management oversight and skills. 
The project manager recognized institutional threats to its business, changes in information technology at the institution, and opportunities for becoming a valuable part of the transitional process. Creation of a plan provided structure and discipline toward taking advantage of these opportunities.

The completion of the project gave the manager a feeling of accomplishment. In order for the project to be successful, it had to have a cohesive plan to provide purpose and direction to the $\mathrm{CRC}$ and its computing-related functions. Trying to implement a "flavor-of-the-month approach to change [is far outweighed by] "integration of various efforts into a coherent picture that people can see, understand, and get behind" (Bateman \& Snell, 1996, p. 555). The most significant aspect of the senior project has been in the successful implementation of new and innovative value-added services that will continue to have a positive impact on both internal and external customers of the Computing Resource Center. 


\subsection{Glossary}

The project report references a number of terms specific to a computing-related procurements and customer service.

Beta testing: The second in a series of system tests prior to release of a computing related software or hardware product to the general public.

Electronic commerce: The sale of products and/or services on the World Wide Web. Electronic software distribution: The process of distributing, downloading, and installing software to a desktop computer from a remote location.

Hardware maintenance agreement: On demand repair services for computer hardware that has been enrolled in a contractual agreement with a service provider. Service options may range from a five-day per week, nine hours per day repair with next day response to a seven-days per week, 24 hours per day repair with a four-hour response.

Internet: A matrix of networks that connects computers around the world.

Intranet: A matrix of networks that connects computers within a specified area, usually a company or organization.

Software maintenance agreement: Ensures free upgrades and updates to specific software for a specified term for those enrolled in the agreement. Other services may include consultation and technical support for problem resolution.

Technical support: Computer support technicians trained in the field of hardware and software repair and troubleshooting.

Value-added service: Providing a unique solution to a customer problem, delivery of a service beyond the norm, or creation of a product or service that people don't even know they need yet.

World Wide Web: An information server on the Internet composed of interconnected sites and files, accessible with a browser. 


\subsection{Works cited}

Bateman, T.S. \& Snell, S.A. (1996). Management: Building competitive advantage. New York: McGraw-Hill.

Blanding, W. (1991). Customer service operations, The complete guide. New York: Amacom.

Chakrapani, C. (1998). How to measure service quality \& customer satisfaction. Chicago: American Marketing Association.

Halbrooks, J.R. (Ed.). (1996). How to really deliver superior customer service. Boston: Goldhirsh Group.

Lees-Haley, P.R. (1980). The questionnaire design handbook. Huntsville, AL: LeesHaley Associates.

Maira, A., \& Scott-Morgan, P. (1997). The accelerating organization: Embracing the human face of change. New York: McGraw-Hill.

Seybold, P B. with Marshak, R.T. (1998). Customers.com. New York: Times Books.

Zikmund, W.G.\& d'Amico, M. (1998). Effective marketing: Creating and keeping customers. Cincinnati, OH: South-Western College. 


\subsection{Appendices}

Appendix A, Project Proposal

Appendix B, Project Plan

Appendix C, Literature Review

Appendix D, Assessments

Appendix E, CRC Customer Service Surveys

Appendix F, Help Desk Call Tracking Statistics

Appendix G, CRC Online Pages

Appendix H, CRC Online Articles

Appendix I, LLNL Software Standards

Appendix J, PC and Mac Desktop Configurations

Appendix K, Statement of Services/Price List and Equipment Schedule

Appendix L, ISM Enrollment Letter

Appendix M, Compaq (Digital) Maintenance Agreement

Appendix N, Grumman Systems Support

Appendix O, Legato Enterprise License for LLNL

Appendix P, Oracle Network License

Appendix Q, Computer Acquisition Specialist 